\title{
Intrinsic resistance to selumetinib, a selective inhibitor of $M E K I / 2$, by cAMP-dependent protein kinase $A$ activation in human lung and colorectal cancer cells
}

\begin{abstract}
T Troiani', L Vecchione',2, E Martinelli', A Capasso', S Costantino ${ }^{3}$, LP Ciuffreda ${ }^{3}$, F Morgillo', D Vitagliano', E D’Aiuto ${ }^{4}$, R De Palma ${ }^{4}$, S Tejpar ${ }^{2}$, E Van Cutsem ${ }^{2}$, M De Lorenzi ${ }^{5,6}$, M Caraglia ${ }^{7}$, L Berrino ${ }^{3}$ and F Ciardiello*,i

'Oncologia Medica, Dipartimento Medico-Chirurgico di Internistica Clinica e Sperimentale F. Magrassi e A. Lanzara, Seconda Università degli Studi di Napoli, Via S. Pansini 5, Napoli 80131 , Italy; ${ }^{2}$ Department of Digestive Oncology, University Hospital Gasthuisberg, Herestraat 49 bus 602 Leuven 3000 , Belgium; ' ${ }^{3}$ Sezione di Farmacologia, Dipartimento di Medicina Sperimentale, Seconda Università degli Studi di Napoli, Via L. De Crecchio 7, Napoli 80 I 38 , Italy; ${ }^{4}$ Immunologia Clinica, Dipartimento Medico-Chirurgico di Internistica Clinica e Sperimentale F. Magrassi e A. Lanzara, Seconda Università degli Studi di Napoli, Via S. Pansini 5, Napoli 80131, Italy; ${ }^{5}$ Département de Formation et Recherche, Centre Hospitalier Universitaire Vaudois, Lausanne, Switzerland; ${ }^{6}$ Swiss Institute of Bioinformatics, Lausanne, Switzerland; ${ }^{7}$ Dipartimento di Biochimica and Biofisica, Via L. De Crecchio 7, Napoli 80 I 38 , Italy
\end{abstract}

BACKGROUND: MEK is activated in 40\% colorectal cancer (CRC) and 20-30\% non-small cell lung cancer (NSCLC). Selumetinib is a selective inhibitor of MEKI/2, which is currently in clinical development.

METHODS: We evaluated the effects of selumetinib in vitro and in vivo in CRC and NSCLC cell lines to identify cancer cell characteristics correlating with sensitivity to MEK inhibition.

RESULTS: Five NSCLC and six CRC cell lines were treated with selumetinib and classified according to the median inhibitory concentration $\left(I_{50}\right)$ values as sensitive $(\leqslant I \mu \mathrm{M})$ or resistant $(>I \mu \mathrm{M})$. In selumetinib-sensitive cancer cell lines, selumetinib treatment induced GI cell-cycle arrest and apoptosis and suppression of tumour growth as xenografts in immunodeficient mice. Evaluation of intracellular effector proteins and analysis of gene mutations showed no correlation with selumetinib sensitivity. Microarray gene expression profiles revealed that the activation of CAMP-dependent protein kinase A (PKA) was associated with MEK inhibitor resistance. Combined targeting of both MEK and PKA resulted in cancer cell growth inhibition of MEK inhibitor-resistant cancer cell lines in vitro and in vivo.

CONCLUSION: This study provides molecular insights to explain resistance to an MEK inhibitor in human cancer cell lines.

British Journal of Cancer (2012) I 06, 1648-1659. doi:I0.1038/bjc.2012.129 www.bjcancer.com

(C) 2012 Cancer Research UK

Keywords: selumetinib; PKA; gene expression; gene mutations; cancer cell resistance

The current approach to drug design in oncology is aimed at modulating specific cell signalling pathways that are important for tumour growth, survival, invasion, and metastasis (Hahn and Weinberg, 2002; Hanahan and Weinberg, 2011). In cancer cells, these pathways become deregulated resulting in aberrant signalling, inhibition of apoptosis, increased metastasis, and increased cell proliferation (Adjei and Hidalgo, 2005). Although normal cells integrate multiple signalling pathways for controlled growth and proliferation, tumours seem to be heavily reliant on activation of one or more pathways. It is conceivable that tumours that are 'driven' by a particular pathway will respond to therapeutics that target components of that pathway. One of the most challenging aspects of anticancer therapy is that patients may exhibit intrinsic or acquired drug resistance and, for most anticancer agents, despite intensive preclinical and clinical studies, the bases for drug resistance remain poorly understood. Therefore, it is crucial to identify biomarkers that may be used to predict cancer cell sensitivity to molecular targeted agents to recognise a molecular

*Correspondence: Dr F Ciardiello; E-mail: fortunato.ciardiello@unina2.it Revised 8 March 2012; accepted I4 March 2012 profile of patient's tumour to guide appropriate therapeutic choices (Downward, 2006).

The RAS/RAF/MEK/ERK signalling pathway is constitutively activated in several cancers, leading to uncontrolled cell proliferation, resistance to apoptosis and association with a more aggressive neoplastic phenotype (Sebolt-Leopold, 2004). Constitutive activation of the MAPK pathway may also contribute to cancer cell resistance to chemotherapy in several types of human malignancies, including pancreatic, colon, lung, thyroid, and breast cancers (Hoshino et al, 1999; Mueller et al, 2000). Signalling through this pathway occurs following activation of cell surface growth factor receptors by extracellular ligands, constitutive activation of cell surface growth factor receptors by gene mutation or protein overexpression, or through gain-of-function gene mutations of BRAF and RAS family members (Adjei, 2001). Activating mutations in $R A S$ and $B R A F$ typically shows mutual exclusivity in tumours, suggesting that the proteins encoded by these genes deregulate a common effector pathway. Mutations in KRAS gene occur in $40 \%$ colorectal cancer (CRC) and $20-30 \%$ of non-small cell lung cancer (NSCLC). Mutations in KRAS are associated with resistance to epidermal growth factor receptor (EGFR) inhibitors in CRC (Pao et al, 2005; Lievre et al, 2006; 
Massarelli et al, 2007; Allegra et al, 2009; De Roock et al, 2010). The three RAF isoforms (RAF1, ARAF, and BRAF) activate both MEK1 and MEK2. Moreover, BRAF activating gene mutations are less common in CRC and NSCLC with incidence of $5-10 \%$ and $<5 \%$, respectively (Brose et al, 2002; Yuen et al, 2002).

Selumetinib (AZD6244, ARRY-142886) is an oral, non-adenosine-5'-triphosphate (ATP) competitive inhibitor and is highly specific for MEK1/2. It is a potent, tight-binding, non-competitive MEK inhibitor with an median inhibitory concentration $\left(\mathrm{IC}_{50}\right)$ of $14.1 \mathrm{nmol} \mathrm{L}^{-1}$ against purified MEK1 with no observed inhibition at $10 \mu \mathrm{mol} \mathrm{L}^{-1}$ against $>40$ other serine/threonine kinases (Davies et al, 2007; Yeh et al, 2007). Selumetinib inhibits both basal and induced levels of ERK1/2 phosphorylation in numerous cancer cell lines such as colorectal, pancreatic, hepatocellular, non-small cell lung, and melanoma. It has also shown efficacy in different tumour models. Sustained inhibition of ERK activity in tumour can be achieved at a dose of $10 \mathrm{mg} \mathrm{kg}^{-1}$ per day in mice xenograft studies (Shannon et al, 2009). The safety profile and tolerability of selumetinib has been evaluated in a two-part, multi-centre, increasing dose, phase I clinical study (Adjei et al, 2008). This trial demonstrated the tolerability of selumetinib, with the most common related toxicities being rash, diarrhoea, nausea, and fatigue. Several studies are ongoing to evaluate the activity of selumetinib, as a single agent or in combination with chemotherapy in a variety of tumour types including CRC and NSCLC (Hainsworth et al, 2010; Bekaii-Saab et al, 2011; Bennouna et al, 2011; O’Nail et al, 2011).

Based on the role of the MAPK signalling pathway in CRC and NSCLC, the first objective of the present study has been to evaluate the sensitivity to selumetinib in vitro and in vivo in these two types of cancers by using a panel of different cancer cell lines. Following this initial screening, the goal of the present study has been to identify specific profiles for gene mutations, gene expression and/or intracellular signalling protein expression, which could allow to define different molecular patterns of either sensitivity or resistance to MEK inhibition in a model of 11 CRC and NSCLC cell lines.

\section{MATERIALS AND METHODS}

\section{Drugs}

The MEK1/2 inhibitor selumetinib was generously provided by Astra Zeneca (Macclesfield, UK). 8-cloro-cAMP (8-Cl-cAMP) was purchased from the BioLog Life Science Institute (Bremen, Germany). Synthesis of antisense 18-mer mixed backbone oligonucleotide (MBO) targeted to the $5^{\prime}$-terminal 8-13 codons of human RI $\alpha$ regulatory subunit messenger RNA of cAMPdependent protein kinase A (PKAI) (Tortora et al, 1997a) was previously described (Agrawal et al, 1997). The PKAI antisense oligonucleotide, designated HYB 190, had the following sequence: 5'-GCGTGCCTCCTCACTGGC-3' (Tortora et al, 1997a). A control PKAI antisense oligonucleotide containing four mismatched nucleotides was designated as HYB 239. The mismatched nucleotides in HYB 239 are underlined: 5'-GCATGCATCCGCA CAGGC-3' (Tortora et al, 1997a). Both HYB 190 and HYB 239 contain phosphorothioate- and methylphosphonate-internucleotide linkages. The identity of each oligonucleotide was confirmed by ${ }^{31} \mathrm{P}$ nuclear magnetic resonance. Chemical purity of each MBO was determined by capillary gel electrophoresis, hybridisation melting temperature, and $\mathrm{A}_{269}$ /mass ratio (Agrawal et al, 1997).

\section{Cell lines}

Five human NSCLC cell lines (GLC82, A549, Calu3, H460, H1299) and six human CRC cell lines (GEO, HCT15, HCT116, SW480, SW620, LS174T) were obtained from the American Type Culture Collection (ATCC) (Manassas, VA, USA). All cancer cell lines, except GLC82, GEO, SW620, and LS174T, were cultured in RPMI1640 medium (Invitrogen, Milan, Italy) supplemented with $10 \%$ fetal bovine serum (Lonza, Milan, Italy), $100 \mathrm{U} \mathrm{ml}^{-1}$ penicillin/ streptomycin (Lonza) and were maintained in a humidified incubator. GLC82, GEO, SW620, and LS174T cancer cells were grown in McCoy medium (Lonza) supplemented with $20 \%$ fetal bovine serum (Lonza), $100 \mathrm{U} \mathrm{ml}^{-1}$ penicillin/streptomycin (Lonza). Cancer cell lines were tested by evaluating the mitochondrial DNA immediately after purchase from ATCC and then tested at various intervals to ensure that the mitochondrial DNA had not changed.

\section{Proliferation assay}

Cell proliferation was measured with the 3-(4, 5-dimethylthiazol2-yl)-5-(3-carboxymethxyphenyl)-2-(4sulfophenyl)-2H-tetrazolium (MTT) assay. Briefly, cell suspensions $(2000 \mu \mathrm{l})$ containing 10000-15000 viable cells were plated into each well and incubated for $48 \mathrm{~h}$ before exposure with different concentrations of selumetinib $(0.01,0.05,0.25,1,5$, and $10 \mu \mathrm{M}), 8$-Cl-cAMP $(0.01,0.05,0.25,1$, 2.5 , and $5 \mu \mathrm{M})$, oligonucleotide HYB $190(0.01,0.05,0.25,1,2.5$, and $5 \mu \mathrm{M})$, or oligonucleotide HYB $239(0.01,0.05,0.25,1,2.5$, and $5 \mu \mathrm{M})$, as previously reported (Morgillo et al, 2011). Each experiment was done in triplicate. The $\mathrm{IC}_{50}$ values were determined by using the CurveExpert 1.3 software (Curve Expert, Mississippi, MS, USA) and plotted in a dose response curves. For the combination experiments, cancer cells were treated with different concentrations of selumetinib $(0.01-5 \mu \mathrm{M})$ plus 8-Cl-cAMP $(0.01-5 \mu \mathrm{M})$, HYB 190 $(0.01-5 \mu \mathrm{M})$, or HYB $239(0.01-5 \mu \mathrm{M})$ plus selumetinib each day, for a total of 3 days, at the fixed drug ratio selumetinib 8-Cl-cAMP of $1: 1$, and selumetinib HYB190 or HYB 239 of $1: 1$. The results of the combination treatment with selumetinib and 8-Cl-cAMP were analysed according to the method of Chou and Talalay by using the CalcuSyn software programme (Biosoft, Cambridge, UK).

\section{Apoptotic assay and analysis of cell cycle}

HCT116, HCT15, Calu3, and H460 cells were collected in six-well plates, treated for 24,48 , and $72 \mathrm{~h}$ with selumetinib $(0.25 \mu \mathrm{m}$ for HCT116, $0.05 \mu \mathrm{m}$ for Calu3, and $10 \mu \mathrm{m}$ for both HCT15 and H460) and stained with Annexin V-FITC. Apoptotic cell death was assessed by counting the numbers of cells that stained positive for Annexin V-FITC and negative for propidium iodide using an Apoptosis Annexin V-FITC Kit (Invitrogen), coupled with fluorescence-activated cell sorting analysis. Cell-cycle analysis was done by using flow cytometry on cell pellets that were fixed in $70 \%$ ethanol, washed in PBS, and mixed with RNase (Invitrogen) and propidium iodide (Invitrogen). Each experiment was done in triplicate. Student's $t$-test was used to evaluate the statistical significance of the results. All $P$-values represent twosided tests of statistical significance. All analyses were done with the BMDP New System statistical package version 1.0 for Microsoft Windows (BMDP Statistical Software, Los Angeles, CA, USA).

\section{Immunoblotting}

HCT116, HCT15, Calu3, and H460 cells were seeded into $100 \mathrm{~mm}^{3}$ dishes $24 \mathrm{~h}$ before treatment with selumetinib $(0.05 \mu \mathrm{M})$. The analysis was done as previously described (Morgillo et al, 2011). We used the following antibodies from Cell Signalling Technology (Beverly, MA, USA): EGFR, phospho-EGFR (Tyr1068), MEK1/2, phospho-MEK1/2, p44/42 MAPK, phospho-p44/42MAPK, AKT, p-AKT (Ser473), 4E-BP1 and phospho-4E-BP1 (Thr37/46). The anti-human $\mathrm{RI} \alpha$ mouse antibody was purchased from Transduction Laboratory (Lexington, NY, USA). The following secondary antibodies from Invitrogen were used: goat anti-rabbit $\operatorname{IgG}$ and rabbit anti-mouse IgG. Immunoreactive proteins were visualised by enhanced chemiluminescence (ECL plus; Amersham Italia, Milan, Italy). Each experiment was done in triplicate. Student's 
$t$-test was used to evaluate the potential relationships expression of proteins and selumetinib response. The analysis was done with the BMDP New System statistical package version 1.0 for Microsoft Windows (BMDP Statistical Software).

\section{Tumour xenografts in nude mice}

Four- to six-week-old female balb/c athymic $(\mathrm{nu}+/ \mathrm{nu}+)$ mice were purchased from Charles River Laboratories (Milan, Italy). The research protocol was approved and mice were maintained in accordance with the institutional guidelines of the Second University of Naples Animal Care and Use Committee. The mice were injected subcutaneously with $2.5 \times 10^{6}$ HCT116, HCT15, Calu3, and H460 cancer cells that have been diluted in $200 \mu \mathrm{l}$ of matrigel (BD Biosciences, Milan, Italy). Resulting xenograft tumours were measured daily until tumour volumes of $100-150 \mathrm{~mm}^{3}$ were reached. Mice ( $n=10$ per group) were then randomised to treatment groups to receive vehicle control $(10 \%$ ethanol/10\% cremophor EL/80\%), selumetinib (25 or $50 \mathrm{mg} \mathrm{kg}^{-1}$; oral gavage), twice a day (BID), 8 -Cl-cAMP $\left(0.5 \mathrm{mg} \mathrm{kg}^{-1}\right.$; intraperitoneal injection) twice a week or the combination of both drugs for 21 days. The body weights were monitored daily. At doses of 25 or $50 \mathrm{mg} \mathrm{kg}^{-1}$ twice daily, selumetinib did not cause any apparent harm to the mice. Monitoring of tumour growth was continued until tumours reached $2000 \mathrm{~mm}^{3}$, when mice were killed. Tumour size was evaluated twice per week by calliper measurements using the following formula: $\pi / 6 \times$ larger diameter $\times(\text { smaller diameter })^{2}$. Student's $t$-test was used to evaluate the statistical significance of the results.

\section{Microarray gene expression analysis of cancer cell lines}

Agilent microarray analyses were done to assess baseline gene expression profile for each cancer cell line using a one colour labelling microarray system as described before (Morgillo et al,
2011). Data were extracted from slide image by using Agilent Feature Extraction software (v.10.5, Agilent Technology Italy, Milan, Italy). The raw data and associated sample information were loaded and processed by Gene Spring 11.5X (Agilent Technology Italy). For identification of genes significantly altered in resistant cells, total detected entities were filtered by signal intensity value (upper cutoff 100th and lower cutoff 20th percentile) and flag to remove very low signal entities. Data were analysed using Student's $t$-test $(P<0.05)$ with a Benjamini-Hochberg multiple test correction to minimise selection of false positives. Of the significantly differentially expressed RNA, only those with greater than two-fold increase or two-fold decrease as compared with the controls were used for further analysis. Subsequently, hierarchical clustering (condition tree) was applied to the data files. In this way, the relationships between the different groups are shown. The condition tree was displayed as a heat map, based on the expression levels of the probe sets. Functional and network analyses of statistically significant gene expression changes were performed using Ingenuity Pathways Analysis (IPA) 8.0 (Ingenuity Systems, http://www.ingenuity.com). Analysis considered all genes from the data set that met the twofold $(P$-value $<0.05)$ change cut-off and that were associated with biological functions in the Ingenuity Pathways Knowledge Base. The significance of the association between the data set and the canonical pathway was measured in two ways: (1) Ratio of the number of genes from the data set that map to the pathway divided by the total number of genes that map to the canonical pathway is displayed and (2) Fisher's exact test was used to calculate a $P$-value determining the probability that the association between the genes in the data set and the canonical pathway is explained by chance alone.

\section{Evaluation of gene mutations}

All cell lines were plated in $100 \mathrm{~mm}^{3}$ dishes and after $24 \mathrm{~h}$ DNA was extracted using the DNAeasy Mini Kit (Qiagen Inc., Milan, Italy)

A

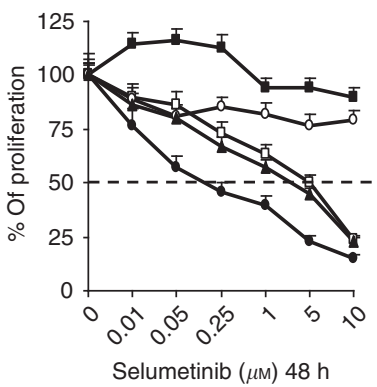

CRC :- GEO - - HCT15 $\rightarrow$ HCT116 - SW480 $\approx$ SW620 $₫$-LS174T
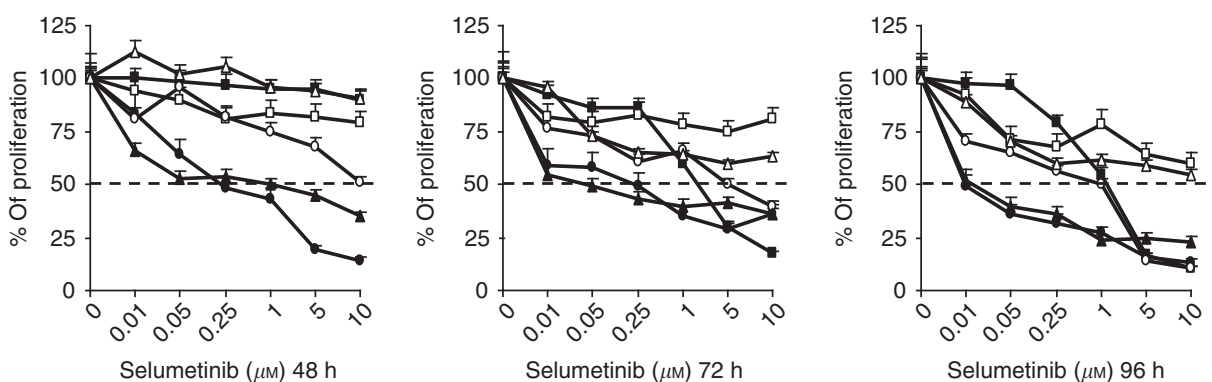

\begin{tabular}{|c|c|c|}
\hline CRC & $\begin{array}{c}\text { Selumetinib }_{(\text {IC50) }} \\
96 \mathrm{~h}\end{array}$ & Sensitivity \\
\hline HCT15 & $>10$ & $\mathrm{R}$ \\
\hline LS174T & 10 & $\mathrm{R}$ \\
\hline GEO & 1 & $\mathrm{~S}$ \\
\hline SW480 & 1 & $\mathrm{~S}$ \\
\hline HCT116 & 0.01 & $\mathrm{~S}$ \\
\hline SW620 & 0.01 & $\mathrm{~S}$ \\
\hline
\end{tabular}

Figure I Effects of selumetinib on cell proliferation in the panel of human $(\mathbf{A})$ NSCLC and (B) CRC cell lines. Cells were treated with increasing concentrations of selumetinib $(0.01-10 \mu \mathrm{M})$ for 48,72 , and $96 \mathrm{~h}$ and evaluated for proliferation by MTT staining, as described in Materials and Methods. The results are average \pm s.d. of three independent experiments each done in duplicate. 
following manufacturer's instructions. We used the COSMIC database (Wellcome Trust Sanger Institute, Catalogue of somatic mutations in cancer. http://www.sanger.ac.uk/genetics/CGP/ cosmic, accessed 15 October 2008) for mutations in KRAS, NRAS, BRAF, PIK3CA, p53, PTEN, MAP2K4 (MEK), AKT, EGFR, occurring in lung and CRC and selected the most frequent mutations per gene. Genomic positions of the mutated nucleotides were downloaded from Ensembl, and $200 \mathrm{bp}$ upstream and downstream sequences were used for primer design with the Sequenom Mass ARRAY, Assay Design 3.1 software (Sequenom, Inc., Hamburg, Germany) using default parameters. Multiplex PCR was performed in a 5- $\mu$ l volume containing 0.5 units of Hotstar Taq polymerase, 5-10 ng of genomic DNA, $100 \mathrm{~nm}$ of each PCR primer, and $500 \mu \mathrm{m}$ of dNTP. Thermocycling was performed at $95{ }^{\circ} \mathrm{C}$ for $15 \mathrm{~min}$, followed by 45 cycles of $94^{\circ} \mathrm{C}$ for $20 \mathrm{~s}, 56^{\circ} \mathrm{C}$ for $30 \mathrm{~s}$ and $72{ }^{\circ} \mathrm{C}$ for $60 \mathrm{~s}$, followed by a final extension of $72{ }^{\circ} \mathrm{C}$ for $3 \mathrm{~min}$. Unincorporated dNTPs were deactivated using 0.3 units of shrimp alkaline phosphatase at $37^{\circ} \mathrm{C}$ for $40 \mathrm{~min}$ and primer extension was carried out using 7-14 $\mu \mathrm{m}$ of each primer extension probe (depending on the mass), 1 unit of iPLEX termination mix, and 1 unit of iPLEX enzyme. Reactions were cycled at $94{ }^{\circ} \mathrm{C}$ for $30 \mathrm{~s}$, followed by 40 cycles of $94{ }^{\circ} \mathrm{C}$ for $5 \mathrm{~s}, 52^{\circ} \mathrm{C}$ for $5 \mathrm{~s}$ and $80^{\circ} \mathrm{C}$ for $5 \mathrm{~s}$, followed by a final extension at $72{ }^{\circ} \mathrm{C}$ for $3 \mathrm{~min}$. After the addition of a cation exchange resin to remove residual salt from the reactions, $20 \mu \mathrm{l}$ of water was added and the extension product was spotted onto a matrix pad (3-hydroxypicoloinic acid) of a Spectro CHIP (Sequenom). After analysing the Spectro CHIPs using a Bruker MALDI-TOF mass spectrometer, spectra were processed by the Spectro READER software (Sequenom) and transferred to the Mass ARRAYTyper 4 Analyser (Sequenom) for further analysis. Genotyping for every sample was performed using the default settings of the Mass ARRAYTyper 4 Analyser. Automated genotyping calls were generated using the Mass ARRAY. The sensitivity of Sequenom gene mutation detection was between $5 \%$ and $15 \%$ and was determined by using DNA from different cell lines. Fisher's exact test was used to determine potential relationships between mutational status and selumetinib response.

\section{RESULTS}

\section{In-vitro inhibition of cell proliferation by selumetinib treatment in NSCLC and CRC cell lines}

We first evaluated the sensitivity to the selective MEK1/2 inhibitor, selumetinib, in a panel of five NSCLC (GLC82, H460, A549, H1299, Calu3) and six CRC (GEO, HCT15, HCT116, SW480, SW620, LS174T) cell lines by using the MTT assay. Cancer cells were treated with selumetinib at concentrations ranging from 0.01 to $10 \mu \mathrm{m}$ for 48,72 , and $96 \mathrm{~h}$. As shown in Figure 1, there was a wide range of sensitivity, with $\mathrm{IC}_{50}$ values varying between 0.01 and $>10 \mu \mathrm{m}$. We classified as sensitive (S) or resistant (R) the cancer cell lines according to selumetinib $\mathrm{IC}_{50}$ at $96 \mathrm{~h} \leqslant 1$ or $>1 \mu \mathrm{M}$, respectively. This concentration was chosen based on the data from phase I studies, which indicated that $1 \mu \mathrm{m}$ was within the average plasma concentrations of selumetinib achieved in patients at the maximum tolerated dose for this agent (Adjei et al, 2008). Overall, 67\% (four of six) CRC and 40\% (two of five) NSCLC cell
A
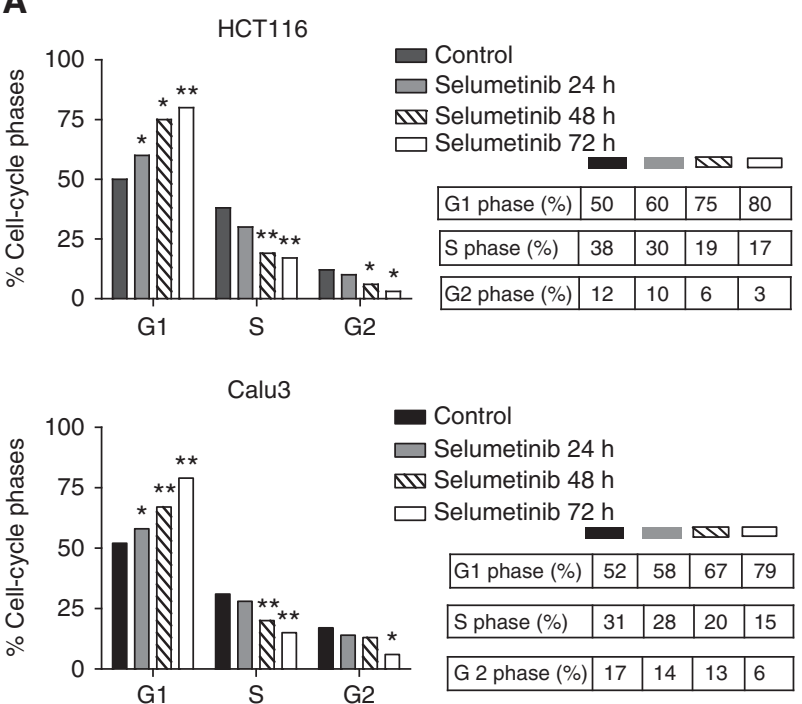

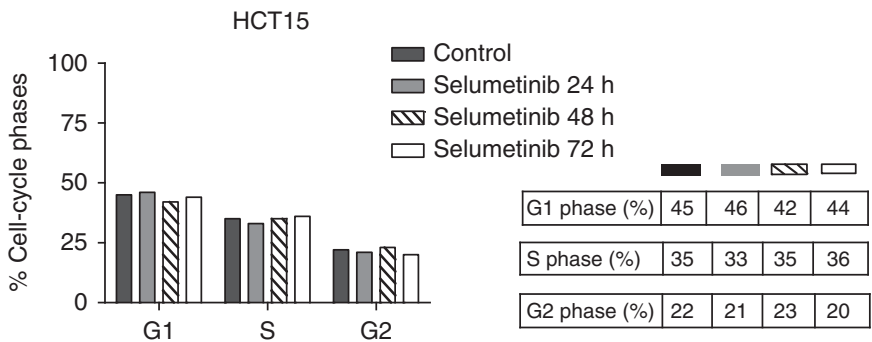

$\mathrm{H} 460$

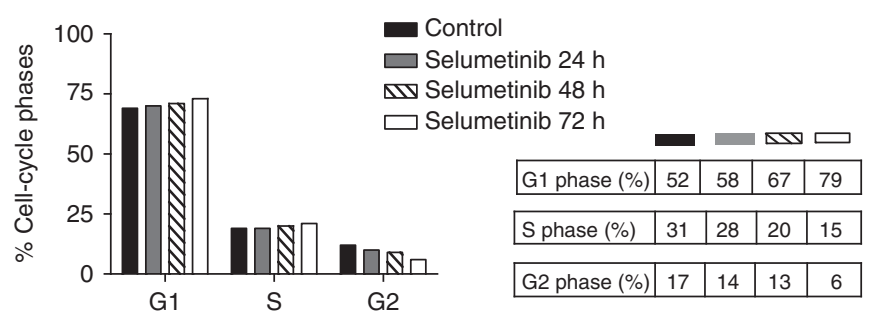

HCT15

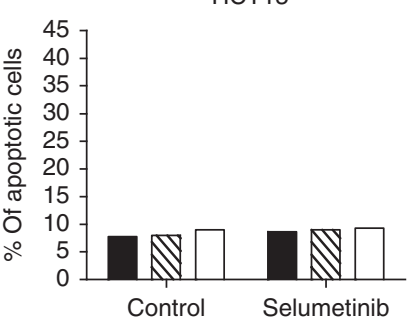

$\mathrm{H} 460$

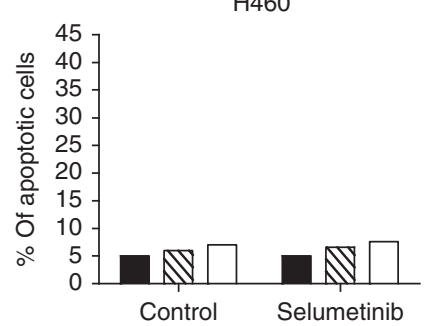

B

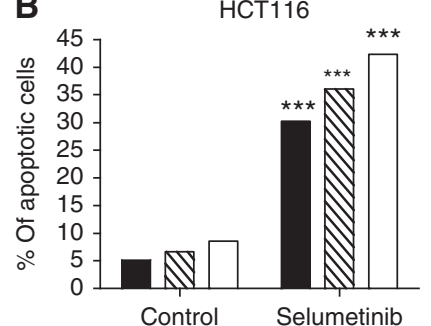

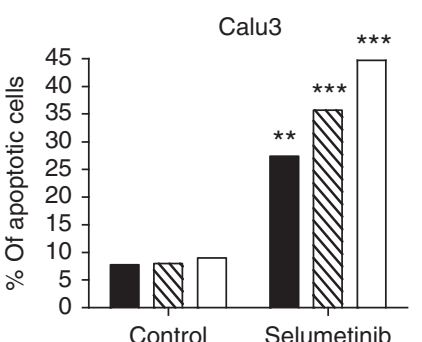

$24 \mathrm{~h} \quad 48 \mathrm{~h} \square 72 \mathrm{~h}$

Figure 2 Effects of selumetinib treatment on cell-cycle distribution $(\mathbf{A})$ and on apoptotic induction (B). HCTI I6, HCTI5, Calu3, and H460 were treated with selumetinib $(0.25 \mu \mathrm{M}$ for HCT I 16, $0.05 \mu \mathrm{m}$ for Calu3, and $10 \mu \mathrm{m}$ for both HCT I 5 and H460) for 24, 48, and $72 \mathrm{~h}$. (A) Flow cytometric analysis of cellcycle distribution was performed as described in Materials and Methods. Percentages of cells in GI, S, and G2 phases of the cell cycle are shown. (B) Apoptosis was evaluated with Annexin $\vee$ staining, as described in Materials and Methods. The rate of apoptosis was expressed as a percentage of the total cells counted. Columns, means of three independent experiments; ${ }^{*} P<0.05$; $* * P<0.005$; ${ }^{*} * * P<0.0005$. 
lines had a selumetinib $\mathrm{IC}_{50}$ of $\leqslant 1 \mu \mathrm{M}$. In particular, among the sensitive cancer cell lines there were four, two NSCLC (Calu3 and H1299) and two CRC (HCT116 and SW620), extremely sensitive to selumetinib with an $\mathrm{IC}_{50}$ of $\leqslant 0.01 \mu \mathrm{M}$ (Figure $1 \mathrm{~A}$ and $\mathrm{B}$ ). To investigate the mechanisms underlying the different sensitivities to the drug, we conducted experiments on a group of four cancer cell lines representing both selumetinib-sensitive (HCT116 and Calu3) and selumetinib-resistant (HCT15 and H460) models.

\section{Effects of selumetinib treatment on cell-cycle distribution in NSCLC and CRC cell lines}

We conducted flow cytometric analysis to compare the cell-cycle distribution following treatment of the selumetinib-sensitive HCT116 and Calu3 cancer cell lines and of the selumetinibresistant HCT15 and H460 cancer cell lines. Cancer cells were treated with selumetinib at the $\mathrm{IC}_{50}$ values for inhibition of cell proliferation for 24,48 , and $72 \mathrm{~h}$. Twenty-four hours selumetinib treatment caused cell accumulation in the G1 phase and concomitant reduction in the $\mathrm{S}$ phase as compared with controls in selumetinib-sensitive cancer cell lines (Figure 2A). The arrest in the G1 phase was significantly increased with longer (48 and $72 \mathrm{~h}$ ) treatment with selumetinib in both HCT116 and Calu3 cells. This effect was also paralleled by a time-dependent reduction in the $\mathrm{S}$ phase in both selumetinib-sensitive cancer cell lines (Figure 2A). In contrast, no effect was observed on cell-cycle distribution in the two selumetinib-resistant HCT15 and H460 cells (Figure 2A). These results were supported also by Garon et al (2010), in which the block in G1 phase inducted by selumetinib is evident only in sensitive cell lines.

\section{Effects of selumetinib treatment on the induction of apoptosis in NSCLC and CRC cell lines}

Several preclinical models have demonstrated that selumetinib act as a cytotoxic drug rather than cytostatic by inducing proapoptotic activity (Huynh et al, 2007a; Huynh et al, 2007b; Meng et al, 2009; Meng et al, 2010). To confirm this effect, the induction of apoptosis was evaluated using an FACS-based assay for Annexin V and PI staining. After $24 \mathrm{~h}$ of selumetinib treatment, a significant induction of apoptosis was detected in the sensitive HCT116 and Calu3 cancer cell lines, which was maximal following $72 \mathrm{~h}$ of treatment (Figure 2B). Moreover, apoptosis was not detectable following treatment with selumetinib in the two resistant HCT15 and H460 cancer cell lines (Figure 2B).

\section{Effects of selumetinib treatment on intracellular signalling in NSCLC and CRC cell lines}

To assess the effects of selumetinib treatment on key intracellular downstream signalling pathways, western blots were performed to assess total and phosphorylated EGFR and downstream effectors (total MEK1/2, phospho-MEK1/2, total MAPK, phospho-MAPK, total AKT, phospho-AKT, total 4EBP1, and phosho-4EBP1). Cancer cells were evaluated at baseline and at different time points after treatment with selumetinib at $0.05 \mu \mathrm{m}$. No change in total and phosphorylated EGFR expression was observed in both selumetinib-sensitive and selumetinib-resistant cancer cell lines (Figure 3A-D). Treatment with selumetinib caused a timedependent inhibition in phospho-MEK1/2 with a complete signal suppression within 60 or 15 min of treatment in HCT116 and Calu3 cells, respectively (Figure $3 \mathrm{~A}$ and $\mathrm{B}$ ). This inhibition was sustained
A

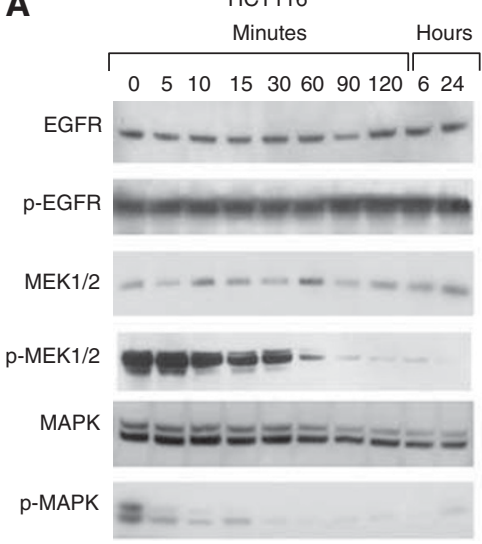

E

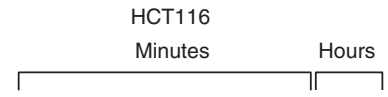
$0 \quad 5 \quad 1015306090120624$

AKT

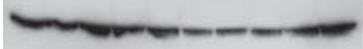

pAKT

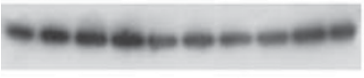

4EBP $1 / 2$

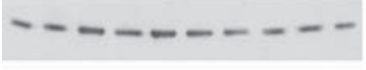

$\mathrm{p}-4 \mathrm{EBP} 1 / 2$

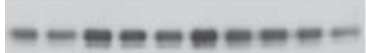

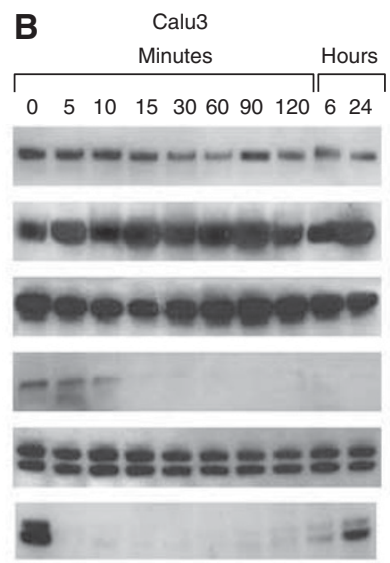

$F$

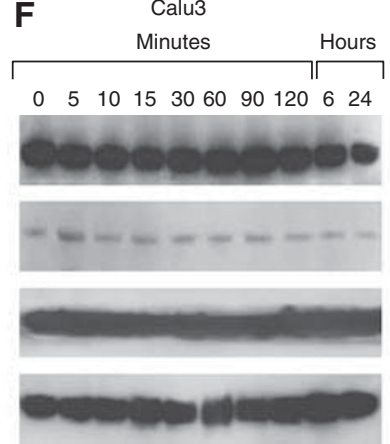

C
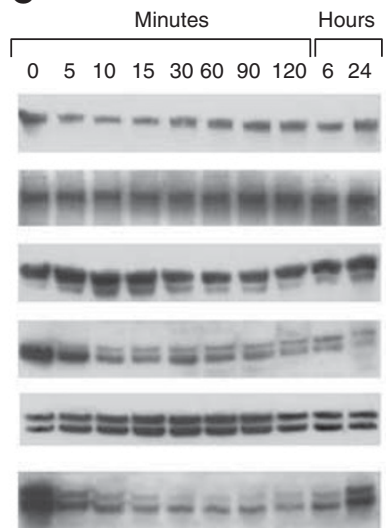

G

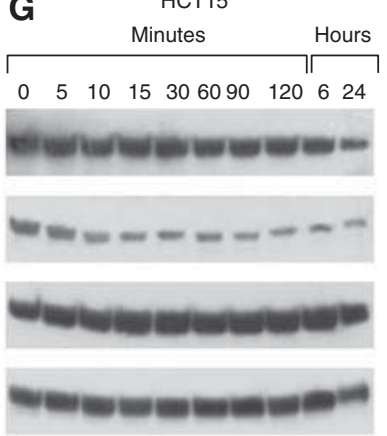

D

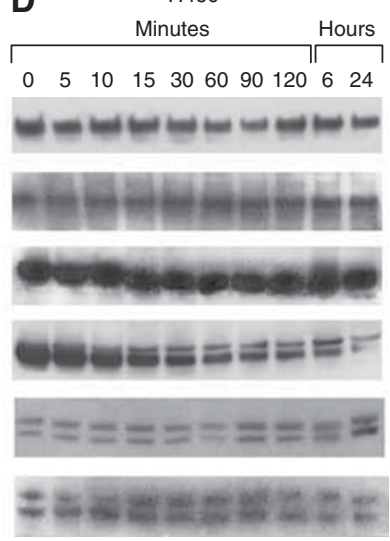

H

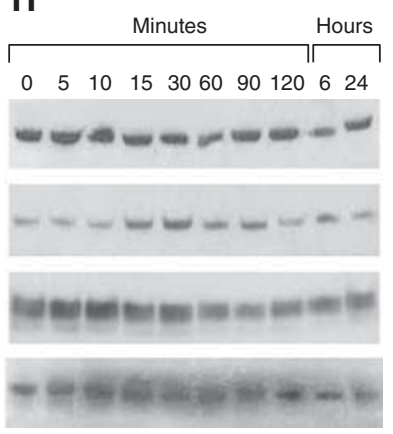

Figure $3(\mathbf{A}-\mathbf{H})$. Western blot analysis of intracellular signalling proteins in selumetinib-sensitive and selumetinib-resistant CRC and NSCLC cell lines. Analysis of intracellular signalling pathways was done by western blotting in two sensitive (HCTI I 6 and Calu3) and two resistant (HCTI 5 and H460) cancer cells treated with $0.05 \mu \mathrm{m}$ selumetinib for the indicated time periods. Total cell protein extracts were fractionated through 4-12\% SDS-PAGE, transferred onto nitrocellulose filters, and incubated with the appropriate antibodies as described in Materials and Methods. Immunoreactive proteins were visualised by enhanced chemiluminescence. Experiments were repeated three times with similar results. 
for $24 \mathrm{~h}$ of selumetinib treatment in both cancer cell lines. In contrast, MEK1/2 inhibition of protein phosphorylation was less effective with only a slight reduction in pospho-MEK1/2 in the two selumetinib-resistant HCT15 and H460 cancer cell lines (Figure 3C and D). Moreover, MAPK phosphorylation was completely blocked following selumetinib treatment in HCT116 and Calu3. In contrast, in the two selumetinib-resistant HCT15 and H460 cells MAPK phosphorylation was only reduced but never completely abrogated (Figure 3C and D). We next assessed the levels of AKT, phosphor$\mathrm{AKT}$, 4EBP1 and poshospho-4EBP1, which are downstream effectors of the PI3 kinase (PI3K) pathway. Previous reports have suggested that resistance to selumetinib treatment in CRC and NSCLC cell lines was associated with baseline increased PI3K signalling (Balmanno et al, 2009). However, as depicted in Figure $3 \mathrm{E}-\mathrm{H}$, we failed to segregate the panel of 11 NSCLC and CRC cell lines into selumetinib-sensitive and selumetinib-resistant groups, by using the PI3K pathway.

\section{Effects of selumetinib treatment on NSCLC and CRC tumour xenografts in nude mice}

As shown in Figure 4A and B, HCT116 and Calu3 xenograft growth was significantly inhibited by selumetinib treatment in a dosedependent manner. As an example, at day 50 from the injection of cancer cells, the mean tumour volume in mice bearing HCT116 tumour xenografts and treated with selumetinib, 25 or $50 \mathrm{mg} \mathrm{kg}^{-1}$ were $40 \%$ and $15 \%$, respectively, as compared with control untreated mice. Similarly, at day 50 from the injection of cancer cells, the mean tumour volume in mice bearing Calu3 tumour xenografts and treated with selumetinib, 25 or $50 \mathrm{mg} \mathrm{kg}^{-1}$ were $22 \%$ and $8 \%$, respectively, as compared with control untreated mice. In contrast, selumetinib treatment was unable to affect tumour growth in both HCT15 and H460 tumour xenografts (Figure $4 \mathrm{C}$ and $\mathrm{D}$ ).

\section{EGFR, RAS, MEK, and AKT protein expression and selumetinib sensitivity in NSCLC and CRC cell lines}

Identification of predictive biomarkers is becoming a fundamental aspect in the development of targeted agents. So far, several preclinical studies have been published trying to address this aspect for the sensitivity to MEK inhibitors, but, since different results have been reported, no univocal interpretation could be made (Balmanno et al, 2009; Dry et al, 2010; Garon et al, 2010; Tendler et al, 2010). To identify specific profiles, which could allow identifying different molecular patterns of sensitivity or resistance to MEK inhibition, we first screened the intracellular signalling status of each cell lines. As depicted in Supplementary Figure 1A, the NCSLC and CRC cell lines displayed highly variable basal levels of total and phosphorylated EGFR, RAS, MEK, and AKT. As illustrated in Supplementary Figure 1B, there was no apparent correlation between basal levels of total and phosphorylated proteins listed above in both tumour types.

\section{Gene mutations and selumetinib sensitivity in NSCLC and CRC cell lines}

Activation of the classic MAPK cascade (RAS-RAF-MEK-ERK) is a common event in colorectal and lung cancer. Some genes within this pathway are mutated or aberrantly expressed. Moreover, the MAPK pathway can be indirectly activated by mutations of genes encoding for PI3K/PTEN/AKT and p53. We have screened the panel of 11 NSCLC and CRC cell lines for mutations in KRAS, NRAS, BRAF, PIK3CA, p53, PTEN, MEK1/2, AKT, EGFR
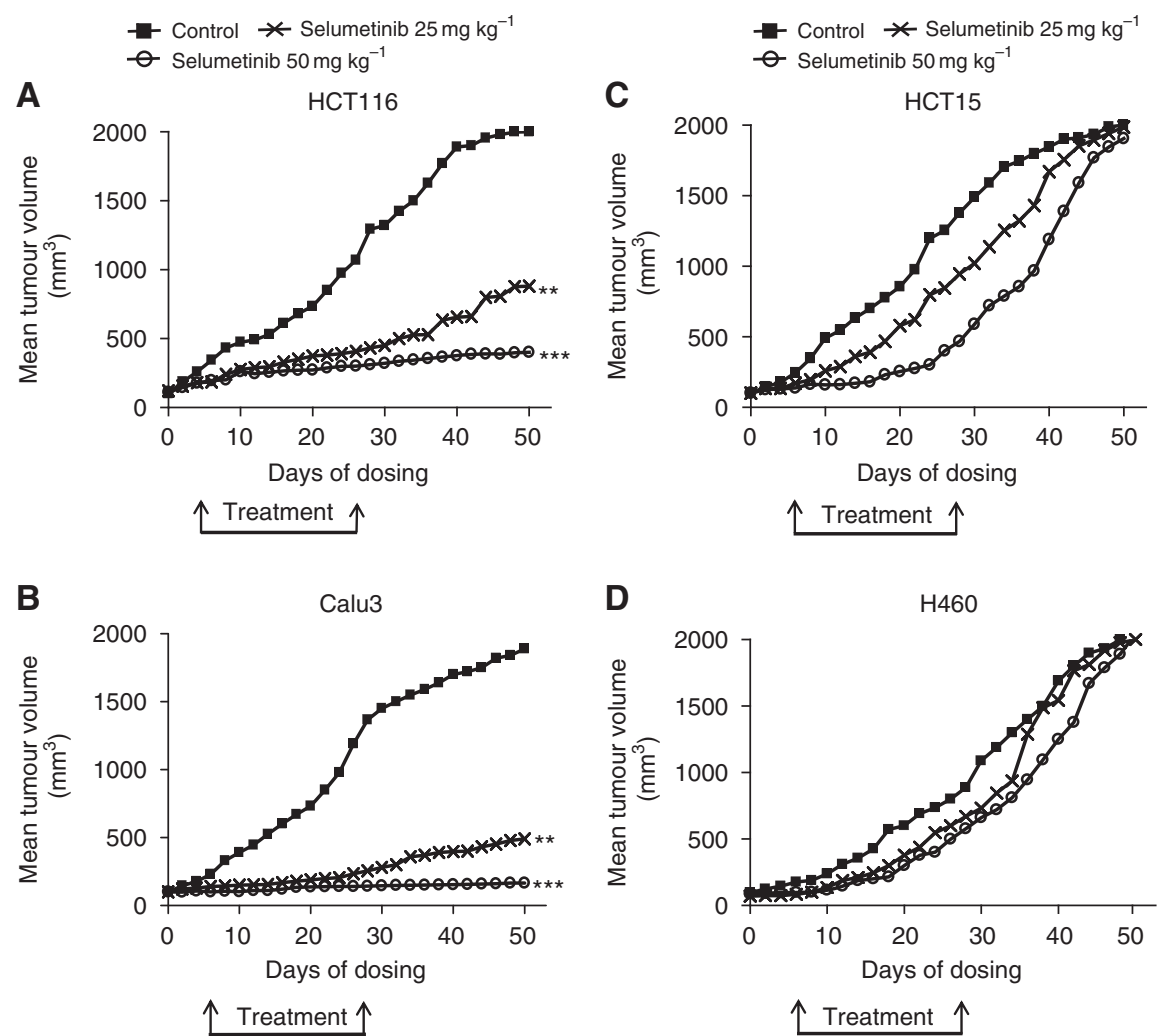

Figure 4 Effects of selumetinib on human CRC and NSCLC xenografts. Mice bearing (A) HCTI I6, (B) Calu3, (C) HCTI5, and (D) H460 cancer cells were treated with vehicle or selumetinib $\left(25\right.$ or $50 \mathrm{mg} \mathrm{kg}^{-1}$, oral, BID) for 21 days ( $n=10$ mice per group). Treatments started when tumour reached volumes of $100-150 \mathrm{~mm}^{3}$. Animals were killed when tumour reached $2000 \mathrm{~mm}^{3}$ in size. $* * * 0<0.005$; $* * * P<0.0005$. 
Table I Mutation status and sensitivity to selumetinib in a panel of NSCLC and CRC cell lines

\begin{tabular}{|c|c|c|c|}
\hline Cell line & Gene & Amino-acid change & Sensitivity \\
\hline GLC82 & PIK $3 C A$ & p.HI047R & $\mathrm{R}$ \\
\hline \multirow[t]{2}{*}{$\mathrm{H} 460$} & PIK $3 C A$ & p.E545K & $\mathrm{R}$ \\
\hline & KRAS & p.Q6IH & \\
\hline \multirow[t]{2}{*}{ A549 } & KRAS & p.GI2S & $\mathrm{R}$ \\
\hline & PIK $3 C A$ & p.Q546K & \\
\hline HI299 & NRAS & p.Q6IK & $\mathrm{S}$ \\
\hline Calu3 & - & - & $\mathrm{S}$ \\
\hline \multirow[t]{2}{*}{ HCTI5 } & KRAS & p.GI3D & $\mathrm{R}$ \\
\hline & PIK $3 C A$ & p.E545K & \\
\hline \multirow[t]{2}{*}{ LSI74T } & KRAS & p.GI2D & $\mathrm{R}$ \\
\hline & PIK $3 C A$ & p.HI047R & \\
\hline GEO & KRAS & p.GI2A & $S$ \\
\hline SW480 & KRAS & p.GI2V & $S$ \\
\hline \multirow{2}{*}{ HCTII 6} & KRAS & p.GI3D & $S$ \\
\hline & PIK $3 C A$ & p.HI047R & \\
\hline SW620 & KRAS & p.GI2V & $S$ \\
\hline
\end{tabular}

Abbreviations: $\quad C R C=$ colorectal cancer; $N S C L C=$ non-small cell lung cancer; $\mathrm{R}=$ resistant; $\mathrm{S}=$ sensitive; $-=$ no mutations.

(Table 1; Supplementary Table 1A-F). In NSCLC cell lines, two out of five $(40 \%)$ harboured a KRAS mutation, which was located in codon 12 or 13 . Moreover, three out of five $(60 \%)$ of NSCLC cells harboured a PI3KCA mutation, which were located in exon 9 or 20. A concomitant mutation in KRAS and PI3KCA gene was found in two out of five $(40 \%)$ NSCLC. One NSCLC cell line had an NRAS mutation (Table 1; Supplementary Table 1A-F). In the panel of six CRC cell lines, all of them harboured a KRAS gene mutation that was located in codon 12 or 13. Moreover, half of CRC cell lines had both a PI3KCA mutation in exon 9 or 20 and a KRAS mutation. None of the CRC cells had an NRAS mutation. No BRAF mutations were observed in the whole panel of NSCLC and CRC cells. As reported in Supplementary Table $1 \mathrm{E}$ and $\mathrm{F}$, no other gene mutations were found in both NSCLC and CRC cell lines. After this screening, we tried to correlate the mutational status with selumetinib sensitivity. The analysis was made either considering separately the two sets of cell lines (data not shown) or all together (Supplementary Figure 2A and B). Sensitivity to selumetinib did not seem to correlate with any specific gene mutations in this panel of NSCLC and CRC cell lines.

\section{Identification of gene expression profiles that could be predictive of response to selumetinib in NSCLC and CRC cell lines}

RNAs from the 11 cancer cell lines were extracted and used for microarray gene expression analysis. Using Student's $t$-test with Benjamini-Hochberg multiple test correction, 21 and 18 genes were identified as upregulated or downregulated, respectively, in selumetinib-resistant cancer cell lines ( $t$-test, $P<0.05)$ (Supplementary Figure 3). Table 2 lists the differentially expressed genes in selumetinib-resistant cancer cell lines. Among the 21 genes that were upregulated in selumetinib-resistant cancer cell lines, we identified two genes, $A D C Y 7$ and $A K A P 13$, which are involved in the cAMP-dependent protein kinase (PKA) pathway (Table 2A; Supplementary Figure 3). The ADCY7 gene encodes a membrane-bound adenylatecyclase that convert ATP into 3', 5'-adenosine monophosphate (cAMP) and pyrophosphate (Supplementary Figure 4). The cAMP is a second messenger that has a key role in intracellular signalling transduction. A major function in mammalian cells is the activation of the PKA (Tasken et al, 1997). The AKAP13 gene encodes the A-kinase anchor protein 13 that has the function of binding to the regulatory subunits of PKA (Supplementary Figure 4). Moreover, four genes (NCOA3, TAF3, NR1H2, and RXRA), which are upregulated in
Table 2 List of the genes that are upregulated (A) and downregulated (B) in selumetinib-resistant CRC and NSCLC cell lines

\begin{tabular}{|c|c|c|c|}
\hline $\begin{array}{l}\text { Gene } \\
\text { symbol }\end{array}$ & Gene name & FC & $P$-value \\
\hline \multicolumn{4}{|l|}{ (A) } \\
\hline LGALS8 & Lectin, galactoside-binding, soluble, 8 & 17265 & 0.000759 \\
\hline$T B \times 3$ & T-box 3 & 9565 & 0.00085 \\
\hline RHOBTB I & Rho-related BTB domain containing I & 534 & 0.010506 \\
\hline EFNA I & Ephrin-AI & 5065 & 0.00475 \\
\hline$C D / 4$ & CDI4 molecule & 4655 & 0.015522 \\
\hline RGPI & $\begin{array}{l}\text { RGPI retrograde golgi transport homologue } \\
\text { (S. cerevisiae) }\end{array}$ & 459 & 0.0035 \\
\hline CKAP4 & Cytoskeleton-associated protein 4 & 432 & 0.000852 \\
\hline & A kinase (PRKA) anchor protein 13 & 3955 & 0.0 \\
\hline A & Retinoid $X$ receptor, alpha & 3935 & 0.0 \\
\hline VASN & Vasorin & 3865 & 0.00355 \\
\hline ADCY7 & Adenylate cyclase 7 & 3835 & 0.004585 \\
\hline & Zinc finger protein 516 & 348 & 0.003229 \\
\hline TAF3 & $\begin{array}{l}\text { TAF3 RNA polymerase II, TATA box binding } \\
\text { protein (TBP)-associated factor, } 140 \mathrm{kDa}\end{array}$ & 3235 & 0.001045 \\
\hline ZNF618 & Zinc finger protein 618 & 322 & 0.0168 \\
\hline NCOA3 & Nuclear receptor co-activator 3 & 306 & 0.020052 \\
\hline BRWDI & $\begin{array}{c}\text { Bromodomain and WD repeat domain } \\
\text { containing । }\end{array}$ & 2955 & 0.023051 \\
\hline AHCYL2 & Adenosylhomocysteinase-like 2 & 2855 & 0.01875 \\
\hline TAOKI & TAO kinase I & 274 & 0.0035 \\
\hline NLK & Nemo-like kinase & 266 & 0.000501 \\
\hline FTL & Ferritin, light polypeptide & 232 & 0.0033 \\
\hline $\mathrm{NR} / \mathrm{H} 2$ & Nuclear receptor subfamily I, group $\mathrm{H}$, & 232 & 0.00385 \\
\hline
\end{tabular}

\begin{tabular}{|c|c|c|c|}
\hline (B) & & & \\
\hline TNIK & TRAF2 and NCK interacting kinase & -1707 & 0.0065 \\
\hline SH3TC2 & $\mathrm{SH} 3$ domain and tetratricopeptide repeats 2 & -9605 & 0.005501 \\
\hline SOBP & $\begin{array}{l}\text { Sine oculis binding protein homologue } \\
\text { (Drosophila) }\end{array}$ & -577 & 0.006542 \\
\hline $100 A 2$ & SI00 calcium binding protein A2 & -5635 & 0.016571 \\
\hline EMTII & Fermitin family homologue I (Drosophila) & -5335 & 0.00084 \\
\hline IILIN2 & Elastin microfibril interfacer 2 & -515 & 0.024016 \\
\hline VLI & Guanine nucleotide binding protein-like I & -347 & 0.015001 \\
\hline NRNPD & $\begin{array}{l}\text { Heterogeneous nuclear ribonucleoprotein D } \\
\text { (AU-rich element RNA binding protein I) }\end{array}$ & -3275 & 0.00345 \\
\hline IF2 & $\begin{array}{c}\text { Inverted formin, } \mathrm{FH} 2 \text { and } \mathrm{WH} 2 \text { domain } \\
\text { containing }\end{array}$ & -3175 & 0.0072 \\
\hline El & Kruppel-like factor 6 & -2985 & 0.016502 \\
\hline MTN & Smoothelin & -297 & 0.024001 \\
\hline KRRI & $\begin{array}{l}\text { KRRI, small subunit (SSU) processome } \\
\text { component, homologue (yeast) }\end{array}$ & -2705 & 0.014356 \\
\hline DI & MAX dimerisation protein I & -27 & 0.0257 \\
\hline B3IP & RAB3A interacting protein (rabin3) & -2525 & 0.01735 \\
\hline SMAGP & Small cell adhesion glycoprotein & -2325 & 0.006003 \\
\hline FAM82B & Family with sequence similarity 82 , member $B$ & -2265 & 0.002593 \\
\hline & Zinc finger protein 180 & -2245 & 0.01795 \\
\hline RPS6KA4 & $\begin{array}{c}\text { Ribosomal protein } 56 \text { kinase, } 90 \mathrm{kDa} \text {, } \\
\text { polypeptide } 4\end{array}$ & -2125 & 0.0229 \\
\hline
\end{tabular}

Abbreviations: $C R C=$ colorectal cancer; $N S C L C=$ non-small cell lung cancer.

selumetinib-resistant cancer cell lines, belong to the retinoic acid pathway, which is also activated by PKA (Altucci et al, 2007).

\section{Treatment with selective PKA inhibitors sensitises selumetinib-resistant cancer cell lines to selumetinib}

To functionally evaluate if the cAMP-dependent PKA could mediate resistance to $\mathrm{MEK}$ inhibitor treatment, we have treated the panel of NSCLC and CRC with 8-Cl-cAMP, a site-selective cAMP analogue, which specifically inhibits PKAI, the PKA isoform that is directly involved in mitogenic signalling and the transformed phenotype (Tortora and Ciardiello, 2000; Naviglio et al, 2009). A dose-dependent inhibition of growth was observed 

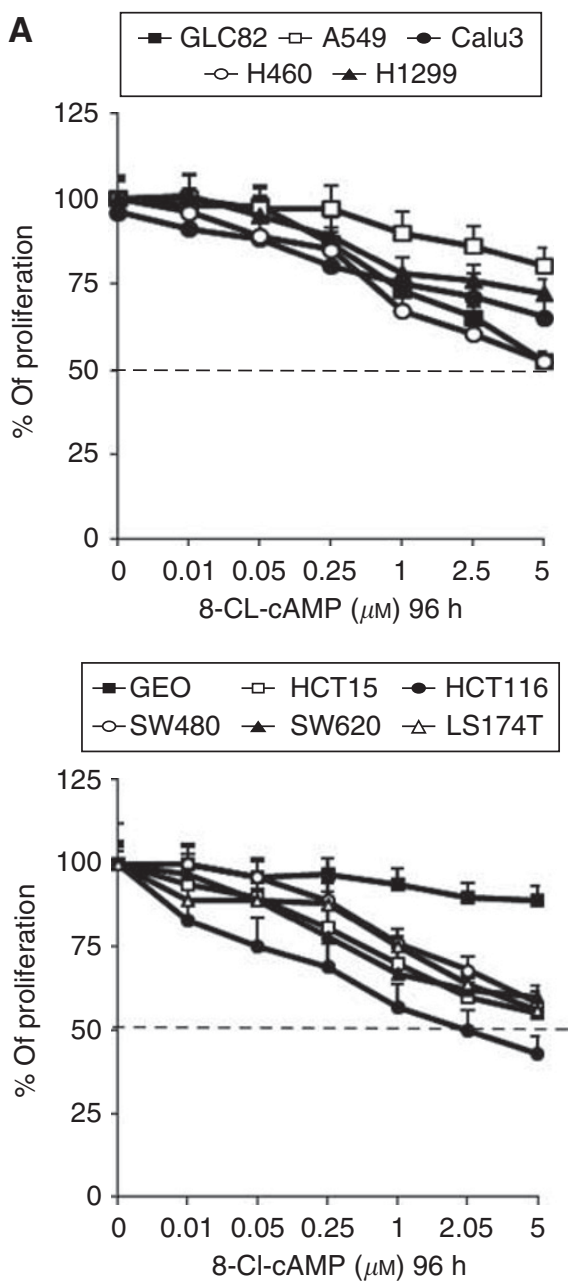

B

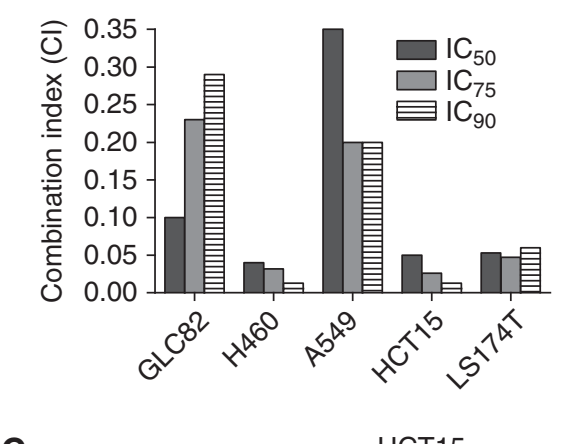

C

$\begin{array}{rlllc}\text { Selumetinib }(\mu \mathrm{M}) & 0 & 0 & 0.5 & 0.5 \\ \text { 8-Cl-cAMP }(\mu \mathrm{M}) & 0 & 1 & 0 & 1\end{array}$

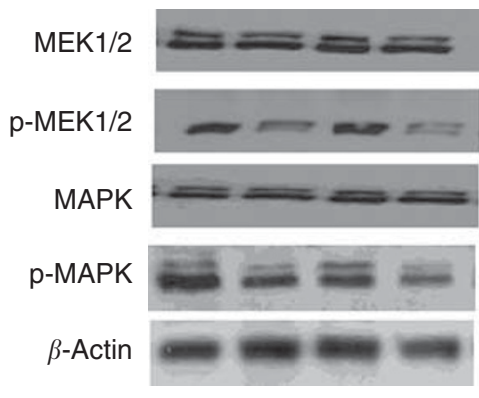

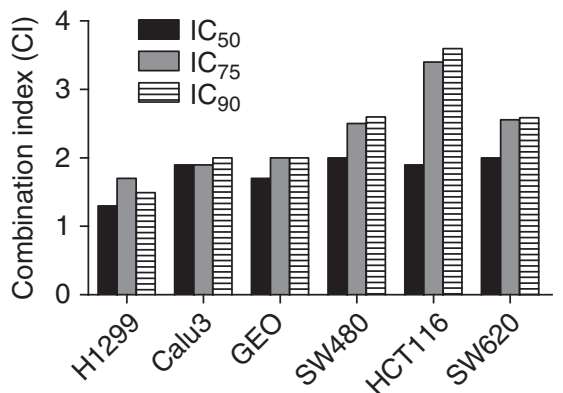
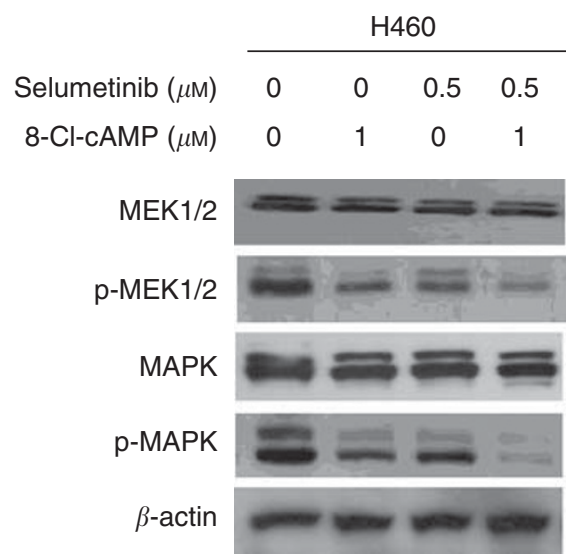

Figure 5 8-Cl-cAMP treatment restores cancer cell sensitivity to MEK inhibition. (A) Cancer cells were treated with increasing concentrations of 8-ClcAMP (range, 0.0I-5 $\mu \mathrm{M}$ ) for $96 \mathrm{~h}$ and evaluated for proliferation by MTT staining, as described in Materials and Methods. The results are average \pm s.d. of three independent experiments each done in duplicate. (B) Cancer cells were treated with different concentrations of selumetinib plus 8-Cl-cAMP as described in Materials and Methods. Experiments were done in triplicate. Cl values were calculated according to Chou and Talalay model for drug interactions using the CalcuSyn software. (C) HCTI5 and H460 cancer cells were treated with selumetinib, 8-Cl-cAMP or selumetinib in combination with 8-Cl-cAMP at the indicated concentrations for $30 \mathrm{~min}$. The cell lysates were immunoblotted with the indicated antibodies, as described in Materials and Methods.

in all cancer cell lines with a different degree of sensitivity, as illustrated in Figure 5A.

To evaluate the interaction between selumetinib and 8-Cl-cAMP, combination analyses were done. The CRC and NSCLC cancer cells were treated with different concentrations of selumetinib (range, $0.01-10 \mu \mathrm{M}$ ) and 8-Cl-cAMP (range, 0.01-5 $\mu \mathrm{M}$ ) each day, for a total of 3 days at a fixed drug ratio selumetinib to 8-Cl-cAMP of $1: 1$. In all selumetinib-resistant cancer cell lines, the combination treatment caused synergistic growth inhibitory effects. In fact, the $\mathrm{CI}$ values for the combinations treatments ranged between 0.013 and 0.350 . This was significantly different in the selumetinib-sensitive cancer cells in which the combination treatment was clearly antagonistic with $\mathrm{CI}$ between 1.3 and 3.6 (Figure 5B).

We next assessed the phosphorylation state of MEK and MAPK following treatment with selumetinib, 8 -Cl-cAMP as single agents or in combination with HCT15 and H460 cancer cell lines. As shown in Figure 3C, single agent selumetinib or 8-Cl-cAMP slightly inhibited p-MEK and p-MAPK, whereas the combination induced a significant inhibition of both phosphorylated proteins.

A genetic approach to inhibiting PKAI expression was developed by the use of phosphorothioate antisense oligonucleotides targeting the synthesis of the PKAI regulatory subunit RI $\alpha$. These oligonucleotides inhibit growth of several human cancer cell lines in vitro and in vivo (Yokozaki et al, 1993; Nesterova and Cho-Chung, 1995; Tortora et al, 1997a). Therefore, HYB 190, an 18 -mer MBO antisense to the N-terminal 8-13 codons of the RI $\alpha$ subunit of PKAI, and the control HYB 239, containing four mismatched bases, were tested to study the effect on the growth of NSCLC and CRC cell lines. All cancer cell lines treated with HBY 190 displayed a dose-dependent inhibition of growth by MTT assay (Figure 6A). Growth inhibition was more pronounced in selumetinib-resistant cancer cell lines $\left(\mathrm{IC}_{50}\right.$ between 0.25 and $1 \mu \mathrm{M}$ ), while the $\mathrm{IC}_{50}$ values were $>5 \mu \mathrm{M}$ in the selumetinibsensitive cancer cells. In contrast, the control oligonucleotide, HYB 239 , at doses up to $5 \mu \mathrm{M}$, showed only $5-15 \%$ growth inhibition among all of the cell lines tested (Figure 6A). To determine whether a combination of selumetinib and oligonucleotide HYB 190 could enhance the antiproliferative effect compared with either agent alone, selumetinib-resistant cells were treated with different combinations of the two agents at a fixed drug ratio of $1: 1$. As shown in Figure 6B, the combination treatment caused synergistic growth inhibitory effects. To determine whether the growth inhibitory effect of oligonucleotide HYB 190 correlated with a reduction in $\mathrm{RI} \alpha$ protein levels, we performed protein blots on total cell extracts prepared from $\mathrm{H} 460$ cells treated with 
A
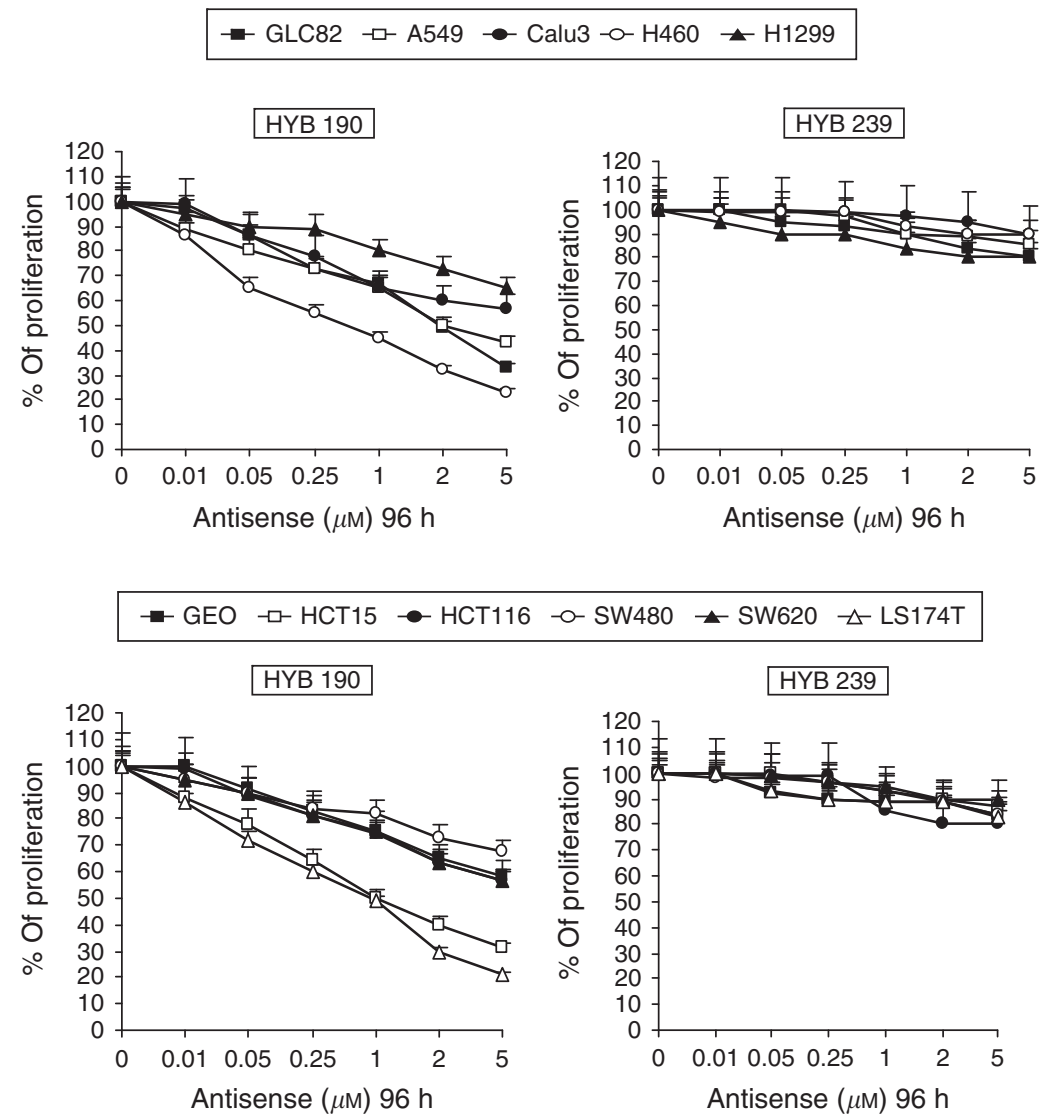

- SW480 $\leftarrow$ SW620 $\triangle$ LS174T

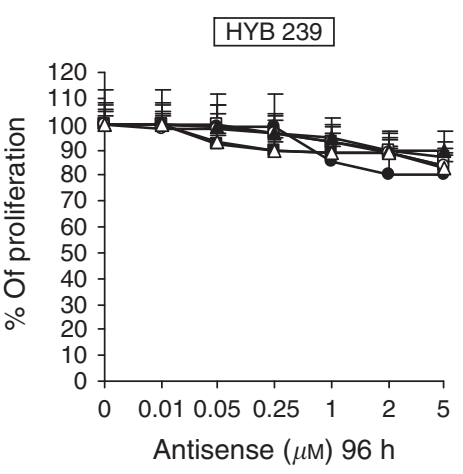

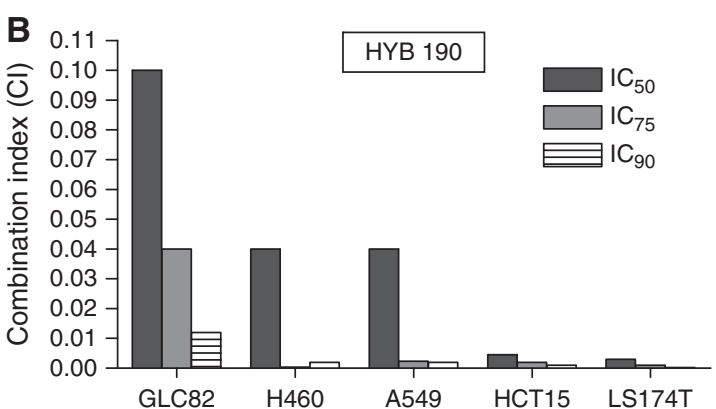
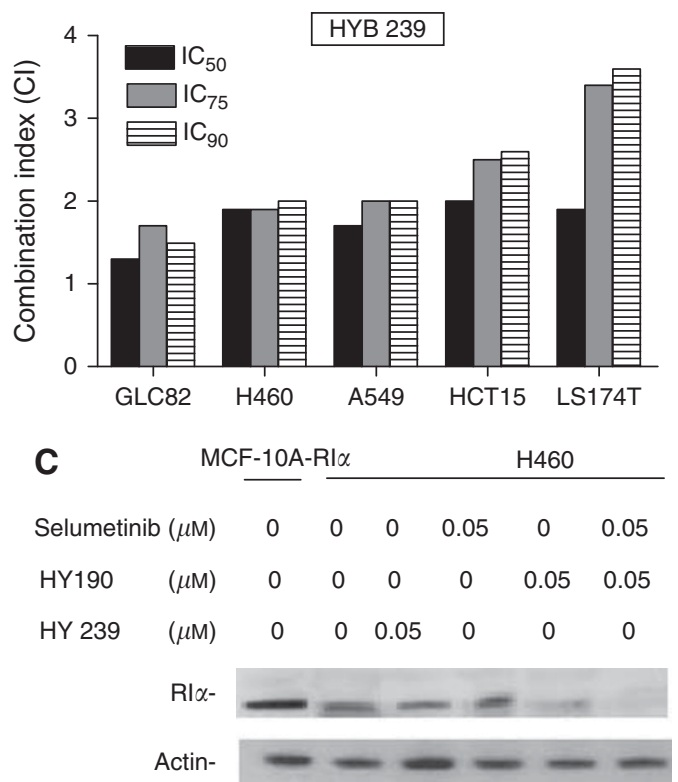

Figure 6 Rl $\alpha$ HYB 190 antisense restores cancer cell sensitivity to MEK inhibition. (A) Cancer cells were treated with increasing concentrations of Rl $\alpha$ antisense HYB 190 and its control sequence HYB 239 (range, $0.0 \mathrm{I}-5 \mu \mathrm{M}$ ) for $96 \mathrm{~h}$ in different cancer cell lines and evaluated for proliferation by MTT staining, as described in Materials and Methods. The results are average \pm s.d. of three independent experiments each done in duplicate. (B) Cancer cells were treated with different concentrations of selumetinib plus Rl $\alpha$ antisense HYB 190 or HYB 239 as described in Materials and Methods. Experiments were done in triplicate. $\mathrm{Cl}$ values were calculated according to Chou and Talalay model for drug interactions using the CalcuSyn software. (C) H460 cancer cells were treated with selumetinib, HYB 190, HYB 239, or selumetinib in combination with HYB 190 or HYB 239 at the indicated concentrations for 4 days. The cell lysates were immunoblotted with specific anti-Rl $\alpha$ monoclonal monoantibody, as described in Materials and Methods.

oligonucleotide HYB 190, oligonucleotide HYB 239, selumetinib, and combinations. Compared with untreated $\mathrm{H} 460$ cells, RI $\alpha$ levels were substantially unchanged, even in cells treated with a higher dose of the control oligonucleotide HYB $239(1 \mu \mathrm{M})$ and selumetinib $(5 \mu \mathrm{M})$. However, reduction of $\mathrm{RI} \alpha$ expression was seen when H460 cells were treated with oligonucleotide HYB 190 (Figure 6C). Moreover, a complete inhibition of RI $\alpha$ expression was seen in the combination treatment (Figure 6C).

We finally evaluated whether the combined inhibition of both PKA and MEK pathways would have antitumour activity in vivo in selumetinib-resistant HCT15 and H460 xenografts (Figure 7). At day 50 from cancer cell injection, the mean tumour volume in mice bearing HCT15 and H460 tumour xenografts and treated with selumetinib, $25 \mathrm{mg} \mathrm{kg}^{-1}$, and 8-Cl-cAMP, $0.5 \mathrm{mg} \mathrm{kg}^{-1}$, were $20 \%$ and $16 \%$, respectively, as compared with control untreated mice.

\section{DISCUSSION}

Advances in the understanding of cancer biology have led to the development of novel and more selective anticancer therapies that are aimed to target specific cancer cell signalling pathways. In this respect, cancer patient selection is a key issue for the optimal use of these drugs. Therefore, identification of biomarkers that could be used to predict response to targeted agents is a crucial challenge in cancer drug development. The key role of the RAS/RAF/MEK/ ERK signalling pathway in cancer cell biology and its potential as a therapeutic target in human cancer has been well established in preclinical models and clinical trials (Adjei et al, 2008; Balmanno et al, 2009; Bennouna et al, 2011; Bekaii-Saab et al, 2011; Dai et al, 2011; Dry et al, 2010; Hainsworth et al, 2010; Tendler et al, 2010; O'Nail et al, 2011). Highly selective small molecule MEK inhibitors have shown clinical activity in different cancers including colon and lung cancer in early clinical trials (Hainsworth et al, 2010; Bennouna et al, 2011).

In this study, we have used selumetinib, a selective inhibitor of MEK1/2 kinases, in a panel of five human NSCLC and six human CRC cell lines. We observed a wide range of in-vitro sensitivity to selumetinib. We considered selumetinib-sensitive cancer cell lines those in which the in-vitro $\mathrm{IC}_{50}$ for cell growth inhibition was $>1 \mu \mathrm{m}$. Cell growth inhibition in selumetinib-sensitive cancer cell lines was paralleled by the induction of apoptosis, suggesting a cytotoxic rather than a cytostatic effect of selumetinib. These data are consistent with previous studies that demonstrated that selumetinib-induced apoptosis is mediated by activating the caspase pathways (Huynh et al, 2007b). Moreover, the inability of selumetinib to completely inhibit the phosphorylation of MEK1/2 and MAPK in selumetinib-resistant cancer cell lines suggests that 
A

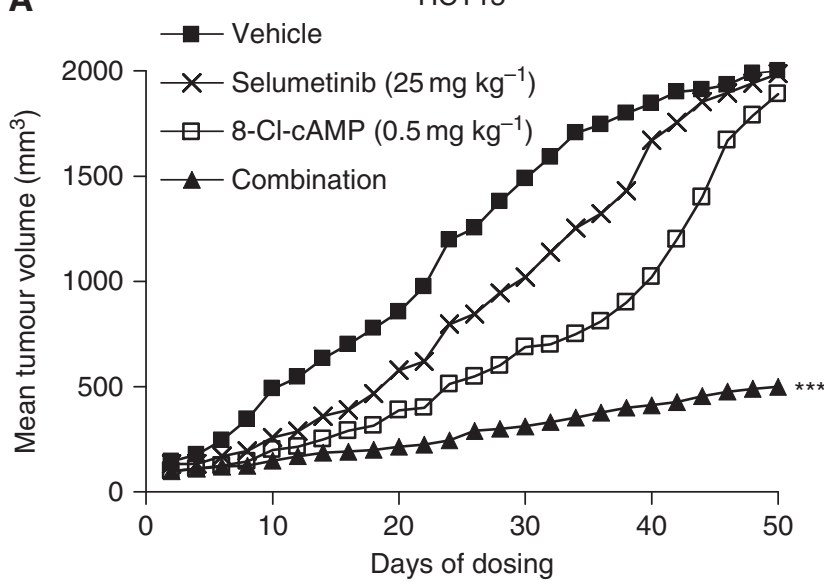

B

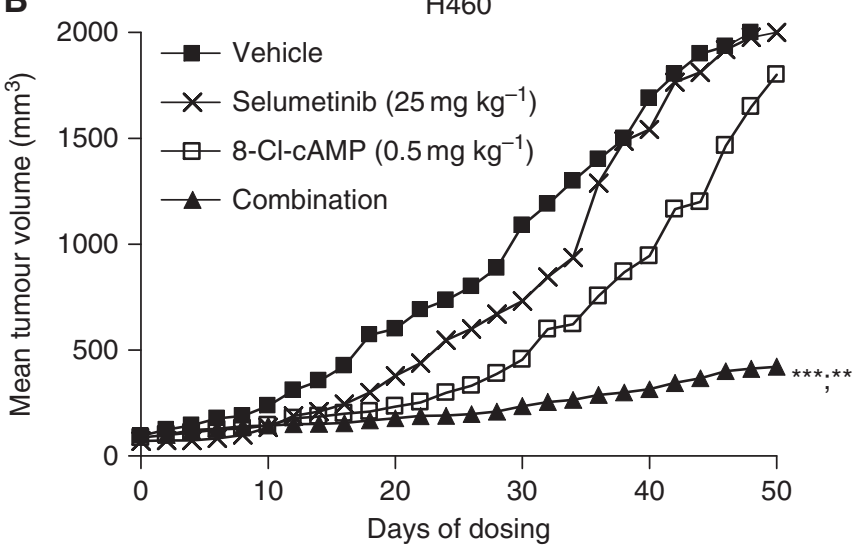

Figure 7 Combined treatment with selumetinib and 8-Cl-cAMP significantly inhibit tumour growth in selumetinib-resistant human tumour xenograft models. (A) HCTI5 and (B) H460 cells were grown as tumour xenografts in nude mice. After tumour establishment $\left(100-150 \mathrm{~mm}^{3}\right)$, mice were treated with selumetinib $\left(25 \mathrm{mg} \mathrm{kg}^{-1}\right.$; oral gavage), twice a day (BID), 8-Cl-cAMP (0.5 $\mathrm{mg} \mathrm{kg}^{-1}$; intraperitoneal injection), twice a week or the combination of both drugs for 21 days. Animals were killed when tumours achieved $2000 \mathrm{~mm}^{3}$ in size. ${ }^{*} * P<0.005$; $* * * P<0.0005$.

the activation of alternative signalling pathways may be responsible of this effect.

We have extensively searched in the panel of NSCLC and CRC cells for mutations of genes coding for proteins involved in the intracellular signalling pathways regulating survival and proliferation and for the expression of the corresponding proteins in an attempt to identify different molecular patterns which could predict sensitivity or resistance to MEK inhibition by selumetinib. No correlation was found between the presence of gene mutations (KRAS, NRAS, BRAF, MEK 1 and 2, p53, PI3KCA, EGFR, PTEN) or protein expression and/or functional activation (MEK, MAPK, RAS, AKT) and sensitivity to selumetinib.

Activation of oncogenes or inactivation of tumour suppressor genes often results in a complex regulation of different cell signalling pathways. Therefore, gene expression profiles could provide more comprehensive means by which to assess the functional consequence of gene mutations and, therefore, may be a more effective tool for a personalised therapeutic approach. Although there are examples for which pathway activation and drug response can be predicted by a single oncogene mutation, it seems more likely that genomic analyses will be necessary to accurately predict response to molecular targeted agents (Lynch et al, 2004; Paez et al, 2004). Analysis of gene expression profiles in the panel of NSCLC and CRC cell lines identified a number of genes whose expression was upregulated or downregulated in selumetinib-resistant cancer cell lines as compared with selumetinib-sensitive ones. Interestingly, several genes which code for proteins that are key regulators of the cAMP-dependent PKA pathway resulted upregulated in selumetinib-resistant cancer cells.

PKA is an intracellular enzyme with serine-threonine kinase activity that has a key role in cell growth and differentiation. The PKA holoenzyme is a tetramer formed of two regulatory (R) subunits and two catalytic (C) subunits. Upon cAMP binding to the $\mathrm{R}$ subunits, the active $\mathrm{C}$ subunit is released and activated (Taylor et al, 1990). PKA is also involved in neoplastic transformation. In this respect, type I PKA (PKAI), which contains the $\mathrm{RI} \alpha$ regulatory subunit, is generally upregulated in human cancer cell lines and primary tumours and is induced following transformation by certain oncogenes, such as RAS (Cho-Chung et al, 1995). Moreover, PKAI overexpression has been correlated with poor prognosis in cancer patients (Miller et al, 1993). Inhibition of PKAI expression and function by specific pharmacologic agents such as the site-selective cAMP analogue 8-Cl-cAMP induces growth inhibition in vitro and antitumour activity in vivo in various human cancer cell lines (Rohlff et al, 1993; Tagliaferri et al, 1988). Experimental evidence has been provided on a functional link between EGFR/RAS-RAF-MEK-ERK pathway and PKAI expression and activity (Ciardiello et al, 1996; Tortora and Ciardiello, 2000). The interaction between EGFR and PKAI occurs through direct binding of the $\mathrm{RI} \alpha$ subunit to the Grb2 adaptor protein. Therefore, PKAI seems to function downstream to the EGFR, and experimental evidence suggests that PKAI is acting upstream to the MAPK pathway (Tortora et al, 1997b). In particular, PKAI provides a relevant contribution to the propagation of EGFR-activated mitogenic intracellular signalling. In fact, overexpression of PKAI in MCF-10A human breast cells determines a constitutive activation of MAPK, mimicking the effect of EGF addition to quiescent MCF-10A cells. In contrast, inhibition of PKAI-mediated signalling by 8-Cl-cAMP significantly reduces MAPK activation in EGF-stimulated MCF- 10A cells (Tortora et al, 1997b). The combined blockade of EGFR and PKAI with selective inhibitors, such as the anti-EGFR blocking monoclonal antibody cetuximab and 8-Cl-cAMP, has a cooperative antitumour activity on human cancer cell lines in vitro and in vivo (Ciardiello et al, 1996). A role of PKAI in neoplastic transformation could be mediated either by the functional and structural connect with ERGF pathway and/or by its relationship with other signalling molecules such as bcl-2-dependent apoptotic pathway and such as tumour-induced neoangiogenesis (Tortora and Ciardiello, 2000).

In the present study, we have shown that treatment with $8-\mathrm{Cl}$ cAMP, a cAMP analogue that specifically inhibits PKAI, is able to overcome the resistance to MEK inhibition in selumetinibresistant cancer cell lines both in vitro and in vivo. These results suggest that the PKA pathway could be activated in human cancer cells with intrinsic resistance to selective MEK inhibitors and represents a rationale for the investigation of combining MEK and PKA inhibitors in cancer treatment.

\section{ACKNOWLEDGEMENTS}

This research has been supported by a grant from the Associazione Italiana per la Ricerca sul Cancro (AIRC), Milan, Italy. T Troiani is the recipient of an ESMO Translational Research Fellowship and this is a major research project during her fellowship program.

\section{Conflict of interest}

The authors declare no conflict of interest.

Supplementary Information accompanies the paper on British Journal of Cancer website (http://www.nature.com/bjc) 


\section{REFERENCES}

Adjei AA (2001) Blocking oncogenic Ras signaling for cancer therapy. $J$ Natl Cancer Inst 93: 1062-1074

Adjei AA, Cohen RB, Franklin WB, Morris C, Wilson D, Molina JR Hanson LJ, Gore L, Chow L, Leong S, Maloney L, Gordon G, Simmons H, Marlow A, Litwiler K, Brown S, Poch G, Kane K, Haney J, Eckhardt SG (2008) Phase I pharmacokinetic and pharmacodynamic study of the oral, small-molecule mitogen-activated protein kinase 1/2 inhibitor AZD6244 (ARRY-142886) in patients with advanced cancers. J Clin Oncol 26: 21392146

Adjei AA, Hidalgo M (2005) Intracellular signal transduction pathway proteins as targets for cancer therapy. J Clin Oncol 23: 5386-5403

Agrawal S, Jiang Z, Zhao Q, Shaw D, Cai Q, Roskey A, Channavajjala L, Saxinger C, Zhang R (1997) Mixed backbone oligonucleotides as second generation antisense oligonucleotides: in vitro and in vivo studies. Proc Natl Acad Sci USA 94: 2620-2625

Allegra CJ, Jessup JM, Somerfield MR, Hamilton SR, Hammond EH Hayes DF, McAllister PK, Morton RF, Schilsky RL (2009) American Society of Clinical Oncology provisional clinical opinion: testing for KRAS gene mutations in patients with metastatic colorectal carcinoma to predict response to anti-epidermal growth factor receptor monoclonal antibody therapy. J Clin Oncol 27: 2091-2096

Altucci L, Leibowitz MD, Ogilvie KM, de Lera AR, Gronemeyer H (2007) RAR and RXR modulation in cancer and metabolic disease. Nat Rev Drug Discov 6: 793-810

Balmanno K, Chell SD, Gillings AS, Hayat S, Cook SJ (2009) Intrinsic resistance to the MEK1/2 inhibitor AZD6244 (ARRY-142886) is associated with weak ERK1/2 signalling and/or strong PI3K signalling in colorectal cancer cell lines. Int J Cancer 125: 2332-2341

Bekaii-Saab T, Phelps MA, Li X, Saji M, Goff L, Kauh JS, O’Neil BH Balsom S, Balint C, Liersemann R, Vasko VV, Bloomston M, Marsh W, Doyle LA, Ellison G, Grever M, Ringel MD, Villalona-Calero MA (2011) Multi-institutional phase II study of selumetinib in patients with metastatic biliary cancers. J Clin Oncol 29: 2357-2363

Bennouna J, Lang I, Valladares-Ayerbes M, Boer K, Adenis A, Escudero P, Kim TY, Pover GM, Morris CD, Douillard JY (2011) A phase II, openlabel, randomized study to assess the efficacy and safety of the MEK1/2 inhibitor AZD6244 (ARRY-142886) versus capecitabine monotherapy in patients with colorectal cancer who have failed one or two prior chemotherapeutic regimens. Invest New Drugs 29: 1021-1028

Brose MS, Volpe P, Feldman M, Kumar M, Rishi I, Gerrero R, Einhorn E, Herlyn M, Minna J, Nicholson A, Roth JA, Albelda SM, Davies H, Cox C, Brignell G, Stephens P, Futreal PA, Wooster R, Stratton MR, Weber BL (2002) BRAF and RAS mutations in human lung cancer and melanoma. Cancer Res 62: 6997-7000

Cho-Chung YS, Pepe S, Clair T, Budillon A, Nesterova M (1995) cAMPdependent protein kinase: role in normal and malignant growth. Crit Rev Oncol Hematol 21: 33-61

Ciardiello F, Damiano V, Bianco R, Bianco C, Fontanini G, De Laurentiis M, De Placido S, Mendelsohn J, Bianco AR, Tortora G (1996) Antitumor activity of combined blockade of epidermal growth factor receptor and protein kinase A. J Natl Cancer Inst 88: 1770-1776

Dai D, Meng J, Peyton M, Girard L, Bornmann WG, Ji L, Minna JD, Fang B, Roth JA (2011) STAT3 mediates resistance to MEK inhibitor through microRNA miR-17. Cancer Res 71: 3658-3668

Davies B, Logie A, McKay J, Martin P, Steele S, Jenkins R, Cockerill M, Cartlidge S, Smith PD (2007) AZD6244 (ARRY-142886), a potent inhibitor of mitogen activated protein kinase/extracellular signal regulated kinase kinase $1 / 2$ kinases: mechanism of action in vivo, pharmacokinetic/pharmacodynamic relationship, and potential for combination in preclinical models. Mol Cancer Ther 6: 2209-2219

De Roock W, Claes B, Bernasconi D, De Schutter J, Biesmans B Fountzilas G, Kalogeras KT, Kotoula V, Papamichael D Laurent-Puig P, Penault-Llorca F, Rougier P, Vincenzi B, Santini D, Tonini G, Cappuzzo F, Frattini M, Molinari F, Saletti P, De Dosso S, Martini M, Bardelli A, Siena S, Sartore-Bianchi A, Tabernero J Macarulla T, Di Fiore F, Gangloff AO, Ciardiello F, Pfeiffer P, Qvortrup C, Hansen TP, Van Cutsem E, Piessevaux H, Lambrechts D, Delorenzi M, Tejpar S (2010) Effects of KRAS, BRAF, NRAS, and PIK3CA mutations on the efficacy of cetuximab plus chemotherapy in chemotherapyrefractory metastatic colorectal cancer: a retrospective consortium analysis. Lancet Oncol 11: 753-762

Downward J (2006) Cancer biology: signatures guide drug choice. Nature 439: $274-275$
Dry JR, Pavey S, Pratilas CA, Harbron C, Runswick S, Hodgson D Chresta C, McCormack R, Byrne N, Cockerill M, Graham A, Beran G, Cassidy A, Haggerty C, Brown H, Ellison G, Dering J, Taylor BS, Stark M, Bonazzi V, Ravishankar S, Packer L, Xing F, Solit DB, Finn RS, Rosen N, Hayward NK, French T, Smith PD (2010) Transcriptional pathway signatures predict MEK addiction and response to selumetinib (AZD6244). Cancer Res 70: 2264-2273

Garon EB, Finn RS, Hosmer W, ering J, Ginther C, Adhami S, Kamranpour N, Pitts S, Desai A, Elashoff D, French T, Smith P, Slamon DJ (2010) Identification of common predictive markers of in vitro response to the Mek inhibitor selumetinib (AZD6244; ARRY-142886) in human breast cancer and non-small cell lung cancer cell lines. Mol Cancer Ther 9: 1985-1994

Hahn WC, Weinberg RA (2002) Modelling the molecular circuitry of cancer. Nat Rev Cancer 2: 331-341

Hainsworth JD, Cebotaru CL, Kanarev V, Ciuleanu TE, Damyanov D Stella P, Ganchev H, Pover G, Morris C, Tzekova V (2010) A phase II, open-label, randomized study to assess the efficacy and safety of AZD6244 (ARRY-142886) versus pemetrexed in patients with non-small cell lung cancer who have failed one or two prior chemotherapeutic regimens. J Thorac Oncol 5: 1630-1636

Hanahan D, Weinberg RA (2011) Hallmarks of cancer: next generation Cell 144: 646-674

Hoshino R, Chatani Y, Yamori T, Tsuruo T, Oka H, Yoshida O, Shimada Y, Ari-i S, Wada H, Fujimoto J, Kohno M (1999) Constitutive activation of the $41-/ 43-\mathrm{kDa}$ mitogen-activated protein kinase signaling pathway in human tumors. Oncogene 18: 813-822

Huynh H, Chow PKH, Soo KC (2007a) AZD6244 and doxorubicin induce growth suppression and apoptosis in mouse models of hepatocellular carcinoma. Mol Cancer Ther 6: 2468-2476

Huynh H, Soo KC, Chow PK, Tran E (2007b) Targeted inhibition of the extracellular signal-regulated kinase pathway with AZD6244 (ARRAY142886) in the treatment of hepatocellular carcinoma. Mol Cancer Ther 6: $138-146$

Lievre A, Bachet JB, Le Corre D, Boige V, Landi B, Emile JF, Côté JF, Tomasic G, Penna C, Ducreux M, Rougier P, Penault-Llorca F, LaurentPuig P (2006) KRAS mutation status is predictive of response to cetuximab therapy in colorectal cancer. Cancer Res 66: 3992-3995

Lynch TJ, Bell DW, Sordella R, Gurubhagavatula S, Okimoto RA, Brannigan BW, Harris PL, Haserlat SM, Supko JG, Haluska FG, Louis DN, Christiani DC, Settleman J, Haber DA (2004) Activating mutations in the epidermal growth factor receptor underlying responsiveness of non-small-cell lung cancer to gefitinib. $N$ Engl J Med 350: 2129-2139

Massarelli E, Varella-Garcia M, Tang X, Xavier AC, Ozburn NC, Liu DD, Bekele BN, Herbst RS, Wistuba (2007) KRAS mutation is an important predictor of resistance to therapy with epidermal growth factor receptor tyrosine kinase inhibitors in non-small-cell lung cancer. Clin Cancer Res 13: $2890-2896$

Meng J, Dai B, Fang B, Bornmann WG, Sun D, Peng Z, Herbst RS, Papadimitrakopoulou V, Minna JD, Peyton M, Roth JA (2010) Combination treatment with MEK and AKT inhibitors is more effective than each drug alone in human non-small cell lung cancer in vitro and in vivo. PLoS One 5: e141240

Meng J, Peng H, Dai B, Guo W, Wang L, Ji L, Minna JD, Chresta CM, Smith PD, Fang B, Roth JA (2009) High level of AKT activity is associated with resistance to MEK inhibitor AZD6244 (ARRAY-142886). Cancer Biol Ther 8: 2073-2080

Miller WR, Watson DMA, Jack W, Chetty U, Elton RA (1993) Tumor cyclic AMP binding proteins: an independent prognostic factor for disease recurrence and survival in breast cancer. Breast Cancer Res Treat 26: 89-94

Morgillo F, Cascone T, D'aiuto E, Martinelli E, Troiani T, Saintigny P De Palma R, Heymach JV, Berrino L, Tuccillo C, Ciardiello F (2011) Antitumor efficacy of MEK inhibitors in human lung cancer cells and their derivatives with acquired resistance to different tyrosine kinase inhibitors. Br J Cancer 105: 382-392

Mueller H, Flury N, Eppenberger-Castori S, Kueng W, David F, Eppenberger U (2000) Potential prognostic value of mitogen-activated protein kinase activity for disease-free survival of primary breast cancer patients. Int J Cancer 89: 384-388

Naviglio S, Caraglia M, Abbruzzese A, Chiosi E, Di Gesto D, Marra M, Romano M, Sorrentino A, Sorvillo L, Spina A, Illiano G (2009) Protein 
Kinase A as a biological target in cancer therapy. Expert Opin Ther Targets 13: 83-92

Nesterova M, Cho-Chung YS (1995) A single-injection protein kinase A-directed antisense treatment to inhibit tumour growth. Nat Med 1: $528-533$

O'Nail BH, Goff LW, Kauh IS, Strosberg JR, Bekaii-Saab TS, Lee RM, Kazi A, Moore DT, Learoyd M, Lush RM, Sebti SM, Sullivan DM (2011) Phase II study of the mitogen-activated protein kinase $1 / 2$ inhibitor selumetinib in patient with advanced hepatocellular carcinoma. J Clin Oncol 29: 235-256

Paez JG, Janne PA, Lee JC, Tracy S, Greulich H, Gabriel S, Herman P, Kaye FJ, Lindeman N, Boggon TJ, Naoki K, Sasaki H, Fujii Y, Eck MJ, Sellers WR, Johnson BE, Meyerson M (2004) EGFR mutations in lung cancer: correlation with clinical response to gefitinib therapy. Science 304: 1497-1500

Pao W, Wang TY, Riely GJ, Miller VA, Pan Q, Ladanyi M, Zakowski MF, Heelan RT, Kris MG, Varmus HE (2005) KRAS mutations and primary resistance of lung adenocarcinomas to gefitinib or erlotinib. PLoS Med 2: e17

Rohlff C, Clair T, Cho-Chung YS (1993) 8-Cl-cAMP induces truncation and down-regulation of the RI $\alpha$ subunit and up-regulation of the RII $\beta$ subunit of cAMP-dependent protein kinase leading to type II holoenzyme-dependent growth inhibition and differentiation of HL-6 leukemia cells. J Biol Chem 268: 5774-5782

Sebolt-Leopold JS (2004) MEK inhibitors: a therapeutic approach to targeting the Ras-MAP kinase pathway in tumors. Curr Pharm Des 10: 1907-1914

Shannon AM, Telfer BA, Smith PD, Babur M, Logie A, Wilkinson RW, Debray C, Stratford IJ, Williams KJ, Wedge SR (2009) The mitogen-activated protein/extracellular signal-regulated kinase kinase $1 / 2$ inhibitor AZD6244 (ARRY-142886) enhances the radiation responsiveness of lung and colorectal tumor xenografts. Clin Cancer Res 15: 6619-6629

Tagliaferri P, Katsaros D, Clair T, Ally S, Tortora G, Neckers L Rubalcava B, Parandoosh Z, Chang YA, Revankar GR, Crabtree GW, Robins RK, Cho-Chung YS (1988) Synergistic inhibition of growth of breast and colon human cancer cell lines by site-selective cAMP analogs. Cancer Res 48: 1642-1650
Tasken K, Skalhegg BS, Tasken KA, Solberg R, Knutsen HK, Levy FO, Sandberg M, Orstavik S, Larsen T, Johansen AK, Vang T, Schrader HP, Reinton NT, Torgersen KM, Hansson V, Jahnsen T (1997) Structure, function, and regulation of human cAMP-dependent protein kinases. Adv Second Messenger Phosphoprotein Res 31: 191-204

Taylor SS, Buechler JA, Yonemoto W (1990) cAMP-dependent protein kinase: framework for a diverse family of regulatory enzymes. Annu Rev Biochem 59: 971-1005

Tentler JJ, Nallapareddy S, Tan AC, Spreafico A, Pitts TM, Morelli MP, Selby HM, Kachaeva MI, Flanigan SA, Kulikowski GN, Leong S, Arcaroli JJ, Messersmith WA, Eckhardt SG (2010) Identification of predictive biomarkers of response to the MEK1/2 inhibitor selumetinib (AZD6244) in K-ras mutated colorectal cancer. Mol Cancer Ther 9: 3351-3362

Tortora G, Caputo R, Damiano V, Bianco R, Pepe S, Bianco AR, Jiang Z, Agrawal S, Ciardiello F (1997a) Synergistic inhibition of human cancer cell growth by cytotoxic drugs and mixed backbone antisense oligonucleotide targeting protein kinase A. Proc Natl Acad Sci USA 94: 12586-12591

Tortora G, Ciardiello F (2000) Targeting of the epidermal growth factor and protein kinase A: molecular basis and therapeutic applications. Ann Oncol 11: 777-783

Tortora G, Damiano V, Bianco C, Baldassarre G, Bianco AR, Lanfrancone L, Pelicci PG, Ciardiello F (1997b) The RI $\alpha$ subunit of protein kinase A (PKA) binds to Grb2 and allows PKA interaction with the activated EGFR-receptor. Oncogene 14: 923-928

Yeh TC, Marsh V, Bernat BA, Ballard J, Colwell H, Evans RJ, Parry J, Smith D, Brandhuber BJ, Gross S, Marlow A, Hurley B, Lyssikatos J, Lee PA, Winkler JD, Koch K, Wallace E (2007) Biological characterization of ARRY-142886 (AZD6244), a potent, highly selective mitogen-activated protein kinase 1/2 inhibitor. Clin Cancer Res 13: 1576-1583

Yokozaki H, Budillon A, Tortora G, Meissner S, Beaucage S, Miki K, ChoChung YS (1993) An antisense oligodeoxynucleotide that depletes RI $\alpha$ subunit of cyclic AMP-dependent protein kinase induces growth inhibition in human cancer cells. Cancer Res 53: 868-872

Yuen ST, Davies H, Chan TL, Ho JW, Bignell GR, Cox C, Stephens P, Edkins S, Tsui WW, Chan AS, Futreal PA, Stratton MR, Wooster R, Leung SY (2002) Similarity of the phenotypic patterns associated with BRAF and KRAS mutations in colorectal neoplasia. Cancer Res 62: 6997-7000

This work is published under the standard license to publish agreement. After 12 months the work will become freely available and the license terms will switch to a Creative Commons Attribution-NonCommercial-Share Alike 3.0 Unported License. 